\title{
Rheological and NMR Studies of Cellulose Dissolution in the lonic Liquid BmimAc
}

\author{
Katherine S. Lefroy, Brent S. Murray, and Michael E. Ries*
}

Cite This: J. Phys. Chem. B 2021, 125, 8205-8218

Read Online

ABSTRACT: Solutions of two types of cellulose in the ionic liquid 1-butyl-3-methyl-imidazolium acetate (BmimAc) have been analyzed using rheology and fast-field cycling nuclear magnetic resonance (NMR) spectroscopy, in order to analyze the macroscopic (bulk) and microscopic environments, respectively. The degree of polymerization (DP) was observed to have a significant effect on both the overlap $\left(c^{*}\right)$ and entanglement $\left(c_{\mathrm{e}}\right)$ concentrations and the intrinsic viscosity $([\eta])$. For microcrystalline cellulose $(\mathrm{MCC}) / \mathrm{BmimAc}$ solutions, $[\eta]=116 \mathrm{~mL} \mathrm{~g}^{-1}$, which is comparable to that of MCC/1-ethyl-3-methyl-imidazolium acetate (EmimAc) solutions, while $[\eta]=350 \mathrm{~mL} \mathrm{~g}^{-1}$ for the commercial cellulose (higher DP). Self-diffusion coefficients (D)

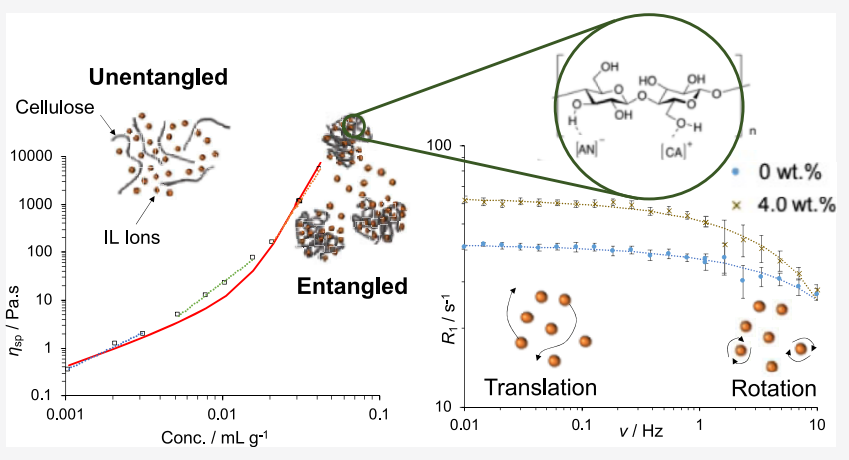
obtained via the model-independent approach were found to decrease with cellulose concentration and increase with temperature, which can in part be explained by the changes in viscosity; however, ion interactions on a local level are also important. Both Stokes-Einstein and Stokes-Einstein-Debye analyses were carried out to directly compare rheological and relaxometry analyses. It was found that polymer entanglements affect the microscopic environment to a much lesser extent than for the macroscopic environment. Finally, the temperature dependencies of $\eta, D$, and relaxation time $\left(T_{1}\right)$ could be well described by Arrhenius relationships, and thus, activation energies $\left(E_{\mathrm{a}}\right)$ for flow, diffusion, and relaxation were determined. We demonstrate that temperature and cellulose concentration have different effects on short- and longrange interactions.

\section{INTRODUCTION}

Ionic liquids (ILs) are made up of a cationic and anionic species and can be defined as low-melting point salts; Walden defined ILs as salts with a melting point below $100{ }^{\circ} \mathrm{C} .{ }^{1,2}$ ILs are non-volatile and potentially recyclable and can be designed for specific processes by altering the cation and anion structures. ${ }^{3}$ Recently, a new class of cholinium- and amino acid-based ILs has emerged, fulfilling the need for ILs to be biodegradable, non-toxic, and safe for producing biocompatible compounds.

ILs have had an enormous impact in the area of cellulose processing, owing in part to their ability to break the strong network of hydrogen bonds that forms between polymer chains. ${ }^{5}$ Mild conditions, relatively easy recovery of cellulose, and potential recyclability of the solvent make ILs superior to many other reported cellulose solvents, such as $N$-methylmorpholine $\mathrm{N}$-oxide, which often require high energy inputs and are thermally unstable. ${ }^{6,7}$ However, high viscosity ${ }^{8}$ and cost of ILs have led to practical issues with their scale-up and have restricted their use in industrial cellulose processing. ${ }^{9}$ Dissolving small amounts of cellulose in an IL can result in a large viscosity increase, which hinders further solubilization ${ }^{10}$ and complicates IL-cellulose handling on a large scale. Furthermore, their ability to dissolve cellulose decreases as the amount of water within the system increases, ${ }^{11}$ since water causes cellulose to coagulate. ${ }^{12,13}$ Almost all ILs are hygroscopic, and as a result, small-scale cellulose dissolution is generally carried out within a sealed system or a glovebox, in order to reduce water vapor uptake from the atmosphere. Dissolution may alternatively require vacuum distillation throughout the process in order to remove water. ${ }^{14}$

Understanding the viscosity-concentration-temperature behavior of cellulose-IL solutions is not only important for the design of processing strategies ${ }^{15}$ but also gives insights into the properties of materials obtained via IL-cellulose processing. ${ }^{16}$ Factors which determine the viscosity and flow properties of the polymer solutions will also affect the morphology of the cellulose material obtained. ${ }^{17}$ For example, it has been shown that cellulose gels coagulated from lower concentration solutions (<ca. $7 \mathrm{wt} \%)$ are relatively

Received: March 30, 2021

Revised: June 29, 2021

Published: July 19, 2021 
heterogeneous, while more concentrated cellulose-IL solutions (>ca. 9 wt \%) yield homogeneous cellulose gels. ${ }^{18}$ Dilute solution viscometry can be employed to gain valuable information about the size and conformation of the macromolecule in solution and the entanglement state, ${ }^{19}$ properties that may be manifested in the coagulated cellulose material. Generally, low-concentration polymer solutions are divided into two regimes, dilute and semi-dilute, in which the viscoelastic behavior differs. ${ }^{20}$ An overlap concentration $\left(c^{*}\right)$ is defined when moving between these two regimes, corresponding to the concentration at which polymer chains start to overlap. ${ }^{21}$ Furthermore, if the polymer molecular weight and critical concentration are sufficiently high, chains may entangle and slow down the dynamics, observed by a second critical concentration, the entanglement concentration $\left.\left(c_{\mathrm{e}}\right)\right)^{22}$ Since the molecular weight of native cellulose is expected to exceed $500,000 \mathrm{Da},{ }^{23}$ all three regimes have been observed for cellulose-IL solutions. ${ }^{15}$ Less overlap is generally required to cause entanglements in polysaccharide solutions compared to synthetic polymers, observed by relatively low values of $c_{\mathrm{e}}[\eta] \simeq 3-5$ for the former compared to $c_{\mathrm{e}}[\eta] \simeq 10$ for the latter, which is in part explained by the inflexibility of polysaccharide chains. ${ }^{22,24}$ Cellulose derivatives also display similar behavior, while charged cellulose polymers can even "hyper-entangle" at higher concentrations, ${ }^{22}$ if attractive interactions are present between chains.

Rheological experiments generally characterize the bulk or macroscopic properties of a polymer solution, which are determined by how much volume the solute occupies in the dilute regime. ${ }^{25}$ On the other hand, it is useful to analyze cellulose-IL solutions on a molecular or microscopic level in order to gain further insights into specific solvent-solute interactions. Nuclear magnetic resonance (NMR) spectroscopy has been successfully applied to the study of cellulose-IL interactions during dissolution, ${ }^{26-29}$ through determination of self-diffusion coefficients $(D) .^{30-32}$ Conventionally, pulsedfield gradient (PFG) NMR experiments at high frequencies are used to determine $D$; however, relaxometry has also been applied to the study of translational diffusion. ${ }^{33-35}$ In fast-field cycling (FFC) NMR relaxometry, the dependence of relaxation time $\left(T_{1}\right)$ is studied as a function of frequency, giving a dispersion (NMRD) profile, from which $D$ can be determined. $T_{1}$ is the result of the intra- and intermolecular interactions, therefore probing the rotational and diffusional motion in solutions, respectively. FFC NMR has previously been used to study the translational dynamics of ILs in polymer systems, where the molecular dynamics of spin nuclei of less-abundant molecules can be probed. ${ }^{36-38}$

Low-field relaxometry experiments at single frequencies have also been used to compare the effects of cellulose, cellobiose, and glucose on the mobility of 1-ethyl-3-methylimidazolium acetate (EmimAc) ions, through measuring $T_{1}$ and $T_{2}$ relaxation times. ${ }^{25}$ Interestingly, it was reported that cellulose solutions gave the longest $T_{1}$ times but the highest viscosities, indicating the highest level of mobility on a molecular scale and the lowest on a macroscopic scale. The authors highlight that the factors affecting the macroscopic and microscopic properties of cellulose/EmimAc solutions are different, and therefore, it is useful to investigate both when considering the dissolution of cellulose.

The solution properties of various types of commercial cellulose powder have been analyzed in EmimAc, ${ }^{6,15,16,39} 1$ butyl-3-methylimidazolium chloride $(\mathrm{BmimCl}),{ }^{16,39}$ and 1- allyl-3-methylimidazolium chloride $(\mathrm{AmimCl}) ;^{40}$ however, to the best of our knowledge, rheological and relaxometry experiments have not been performed with 1-butyl-3methylimidazolium acetate (BmimAc). BmimAc and EmimAc have displayed similar cellulose-dissolving capacities, ${ }^{41,42}$ while alkyl chain length is reported to have no influence over the onset temperature $\left(T_{\text {on }}\right)$, and therefore, both ILs are similar in terms of their safety with respect to industrial processing. ${ }^{14}$ However, BmimAc is slightly cheaper than EmimAc and therefore may be a more affordable approach to IL processing of cellulose. In this work, the bulk properties of lowconcentration cellulose/BmimAc solutions ( $0-4$ wt \%) were analyzed using steady-state flow rheology, and we determine the zero-shear rate viscosities $\left(\eta_{0}\right)$, crossover and entanglement concentrations $\left(c^{*}\right.$ and $\left.c_{\mathrm{e}}\right)$, and intrinsic viscosity $([\eta])$. Two types of cellulose, Vitacel L 00 powder $(V$-cell) and Avicel Microcrystalline Cellulose PH-101 (A-cell), were investigated in order to compare the effect of cellulose molecular weight on solvent properties and to provide a comparison to other cellulose ILs in the literature. FFC NMR relaxometry was then used in order to obtain $D$ values for the solvent at different cellulose concentrations, while relaxation times $\left(T_{1}\right)$ obtained at a single frequency $(10 \mathrm{MHz})$ are reported and analyzed. Finally, macroscopic and microscopic properties of the solutions were compared using Stokes-Einstein and StokesEinstein-Debye equations, correlating the rheological and relaxometry analyses. The solutions were studied over a temperature range using each method, and a classic Arrhenius approach was used to calculate the activation energies and compare the three different processes being probed: flow, diffusional, and rotational motion $\left(E_{\mathrm{a}, \eta}, E_{\mathrm{a}, \mathrm{D}}\right.$, and $E_{\mathrm{a}, \mathrm{T} 1}$ respectively).

Detailed studies of cellulose dissolution in BmimAc will not only provide a comparison between different ILs but also give further insights into the interactions between cellulose and itself and cellulose and the solvent ions. This information will be valuable in understanding the process of cellulose dissolution in ILs and therefore aid the design of more suitable cellulose solvents for larger-scale processing.

\section{METHODS}

Materials. Vitacel powdered cellulose L 00 (JRS, supplied by Mondelez International) [degree of polymerization (DP) $\approx$ 730-830, as estimated below] and Avicel PH-101 microcrystalline cellulose (MCC) (Sigma-Aldrich, DP $\approx 180)^{25}$ were both used to investigate the effect of DP on the viscosity of cellulose in IL solutions. The Vitacel cellulose and the Avicel cellulose are abbreviated to " $V$-cell" and " $A$-cell," respectively. While the DP of $V$-cell is estimated, other known properties such as fiber size are listed in the Supporting Information (Table S1). The IL 1-butyl-3-methyl-imidazolium acetate (BmimAc) ( $\geq 98 \%$ purity, Sigma-Aldrich) was used to dissolve the $A$-cell and $V$-cell.

Preparation of Cellulose-IL Solutions. $A$-cell or $V$-cell powders were first dried in a vacuum oven at $60{ }^{\circ} \mathrm{C}$ for at least $24 \mathrm{~h}$, in order to remove any moisture. A total of $0-4 \mathrm{wt} \%$ of the cellulose was then dissolved in BmimAc in a sealed vial with slow stirring $\left(70{ }^{\circ} \mathrm{C}, 400 \mathrm{rpm}\right)$ using a magnetic stirrer bar, in order to minimize the incorporation of air bubbles. Concentrations greater than 4 wt $\% V$-cell were not investigated since the resultant solutions were highly viscous and inhomogeneous and required long stirring times at higher temperatures, which may lead to cellulose degradation. ${ }^{15,43}$ 
Dissolution was said to be complete when the solution was clear and no particles were visible. Samples were then stored in a desiccator until required, to prevent uptake of any water vapor from the atmosphere by BmimAc.

Rheology. Steady-state viscosity measurements of 0-4 wt $\%$ cellulose/BmimAc solutions were measured using an Anton Paar rheometer, equipped with a water bath temperature control system and a Peltier hood. A $50 \mathrm{~mm}$-diameter circular cone-plate geometry was used, with an angle of $2^{\circ}$. Viscosity measurements were conducted in the range $0.01-1000 \mathrm{~s}^{-1}$ at a constant temperature $\left(25-70{ }^{\circ} \mathrm{C}\right)$, and flow curves were obtained. Each sample was heated to the desired measurement temperature for $1 \mathrm{~min}$ and then pre-sheared for $1 \mathrm{~min}$ at $1 \mathrm{~s}^{-1}$, to ensure adequate heating throughout. Measurements were repeated three times, and an average viscosity value was deduced.

${ }^{1} \mathrm{H}$ NMR (High-Field) Quantitative NMR. ${ }^{1} \mathrm{H}$ NMR spectra for cellulose-BmimAc solutions (0-4 wt \%) were recorded on a wide-bore Avance II NMR spectrometer (Bruker Biospin) operating at a proton resonance frequency of $400 \mathrm{MHz}\left(25^{\circ} \mathrm{C}\right)$. An average water content of $0.44 \pm 0.24$ wt $\%$ was determined for all $V$-cell/BmimAc solutions except for 3 and 4 wt $\%$, which were highly viscous, due to the increased time taken to fill the NMR tube and therefore longer exposure of the IL to air. Therefore, data for these two solutions should be treated with caution, since water contamination is likely to affect the accuracy of the results.

FFC NMR Relaxometry. FFC NMR was conducted on a Stelar SMARtracer FFC NMR relaxometer (Stelar s.r.l., Mede, $\mathrm{PV}$, Italy), generating ${ }^{1} \mathrm{H}$ NMRD dispersion profiles. Glass tubes of $5 \mathrm{~mm}$ diameter (WilmadR, Sigma-Aldrich) were filled with ca. $2.5 \mathrm{~mL}$ of sample and sealed. Samples were analyzed at constant temperatures $\left(25-70{ }^{\circ} \mathrm{C}\right)$, with $10 \mathrm{~min}$ thermal equilibration time allowed after each temperature was reached. Temperature was controlled via a variable temperature controller with an accuracy of $0.1 \mathrm{~K}$. A total of four scans were recorded for each, and an average value of these is reported. $T_{1}$ values were calculated using a single-exponential function, since magnetization decay was monoexponential over the range of frequencies measured, for all samples. During each measurement, a polarization field of $7 \mathrm{MHz}$ was initially applied for a period of approximately five times the $T_{1}$ value estimated at this frequency. The magnetization was then switched to the measurement relaxation field $(0.01-10 \mathrm{MHz})$. A single ${ }^{1} \mathrm{H} 90^{\circ}$ pulse at $7 \mathrm{MHz}$ was then applied, and the free induction decay (FID) was recorded. A non-polarized FFC sequence was applied for all samples over the frequency range measured. A field-switching time of $0.003 \mathrm{~ms}$, a dead time of 15-20 $\mu \mathrm{s}$, and a recycle delay of five times $T_{1}$ were used.

NMRD profiles were fitted to the well-known modelindependent approach, as first described by Kruk et al., ${ }^{34}$ in order to obtain $D$ values for each cellulose concentration over a range of temperatures. Full details of the relaxometry theory, equations, and methods can be found in the Supporting Information.

\section{RESULTS AND DISCUSSION}

Rheological Properties of $A$-Cell/BmimAc. Initially, the flow curves for $A$-cell in BmimAc (0-4 wt \%) were analyzed in order to compare the solvent properties of BmimAc to those of EmimAc and other acetate-based ILs. Figure S1a gives viscosity $(\eta)$ plotted as a function of shear rate $(\dot{\gamma})$ for $0-4$ wt \% $A$-cell at $25{ }^{\circ} \mathrm{C}$. Flow curves were fitted to the well-known Cross model, ${ }^{44}$ as given by

$$
\eta_{(\dot{\gamma})}=\eta_{(\infty)}+\frac{\eta_{(0)}-\eta_{(\infty)}}{1+(C \dot{\gamma})^{m}}
$$

where $\eta_{(0)}=$ zero-shear rate viscosity; $\eta_{(\infty)}=$ infinite-shear rate viscosity; $C=$ Cross time constant, and $m=$ (Cross) rate constant. Both $C$ and $m$ give information on the shear thinning region: $1 / C$ gives the critical shear rate, which is a good indication of the onset of shear thinning, while $m$ gives the degree of the dependence of viscosity on shear (within the shear thinning region). It should be noted that for all of the cellulose-BmimAc solutions, no positive inflexion was observed in the data toward the higher shear rates, and therefore, it was assumed that $\eta_{(\infty)}$ was approximately the value of the pure solvent when fitting the data. Furthermore, only the extrapolated zero-shear rate viscosities were considered for further analysis, and therefore, $\eta_{(0)}$ will be referred to as simply the viscosity, $\eta$.

Viscosity decreases as the concentration of cellulose decreases, as expected for a classical polymer solution. Shear thinning is observed due to alignment of polymer molecules in the shear direction, ${ }^{17}$ and this behavior becomes more pronounced with increasing cellulose concentration, as reported elsewhere for cellulose dissolved in ILs. ${ }^{15,16,40,45}$ This is reflected by the onset of shear thinning, $1 / C$, which is given in Table 1.

Table 1. Values for $\eta, m$, and $1 / C$ for $A$-Cell/BmimAc Solutions (0-4 wt \%) at $25^{\circ} \mathrm{C}$, Obtained by Fitting Data to the Cross Model

\begin{tabular}{ccccc} 
concentration of A-cell/wt \% & $\eta / \mathrm{Pa} \cdot \mathrm{s}$ & $m$ & $\mathrm{C} / \mathrm{s}$ & $1 / \mathrm{C} / \mathrm{s}^{-1}$ \\
0 & 0.390 & 0.891 & 0.001 & 1260 \\
0.1 & 0.446 & 0.316 & 0.001 & 1000 \\
0.2 & 0.468 & 0.794 & 0.001 & 891 \\
0.3 & 0.575 & 0.794 & 0.00115 & 871 \\
0.5 & 0.640 & 0.794 & 0.00120 & 832 \\
0.75 & 0.946 & 0.794 & 0.00126 & 794 \\
1.0 & 1.19 & 0.794 & 0.00129 & 776 \\
1.5 & 1.89 & 0.794 & 0.00158 & 631 \\
2.0 & 2.90 & 0.891 & 0.00178 & 562 \\
3.0 & 5.33 & 0.977 & 0.00182 & 550 \\
4.0 & 9.46 & 0.977 & 0.00344 & 291 \\
\hline
\end{tabular}

For the pure IL and low concentrations of $A$-cell/BmimAc $(<1.0 \mathrm{wt} \%)$, viscosity was largely independent of the shear rate (Newtonian behavior); however, a low-shear rate and shear thinning regime was sometimes observed $\left(\dot{\gamma} \approx 0.01-0.1 \mathrm{~s}^{-1}\right.$, Figure S2). Low shear rate and shear thinning have been reported for $A$-cell in EmimAc ${ }^{6}$ and cellulose dissolved in $\mathrm{AmimCl}^{40}$ and may be explained by IL molecular interactions; it is proposed that in a pure solvent, IL molecules undergo hydrogen bonding with each other and form clusters (left schematic, Figure 1), which can in turn form a dynamic network that begins to gradually break down as the shear rate increases. This behavior is observed despite the introduction of a pre-shear $\left(1 \mathrm{~s}^{-1}\right)$, suggesting that these weak cluster networks are dynamic and reform rapidly. Specific hydrogen bond-type interactions have been similarly reported for other halide-based ILs, ${ }^{46,47}$ while cluster formation in pure ILs has been extensively reported. ${ }^{48}$ At low wt \% cellulose $(0.1-1$ wt \%), this dynamic network of IL molecules is only partially 


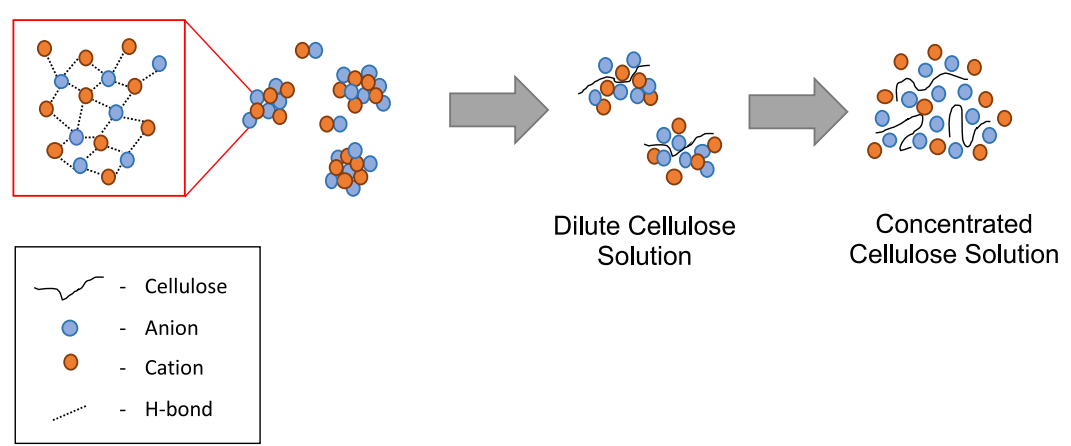

Figure 1. From left to right: schematic to show the formation of H-bonded ion clusters in pure ILs; formation of cellulose-IL clusters at low cellulose concentrations; and breakdown of clusters at higher cellulose concentrations.

disrupted by the presence of polysaccharide chains, and IL aggregates are still present (middle schematic, Figure 1). It is also speculated that cellulose molecules and IL molecules may form dynamic clusters, further contributing to the shear thinning behavior. ${ }^{40}$ Low shear rate and shear thinning behavior begins to disappear as the wt \% cellulose increases, due to significant disruption of the physical IL network and solvation of cellulose chains by the $\mathrm{Bmim}^{+}$cation and $\mathrm{Ac}^{-}$ anion (right schematic, Figure 1).

In order to the compare the solvent properties of BmimAc to those of EmimAc, $\eta$ values extrapolated from flow curves of $A$-cell/BmimAc are listed with the literature values for A-cell/ EmimAc solutions ${ }^{6}$ in Table 2. At concentrations of 0.5 and

Table 2. A-Cell in EmimAc and BmimAc $\left(25^{\circ} \mathrm{C}\right), \boldsymbol{\eta}$ Values Compared with the Viscosity Increase Relative to the Pure Solvent $\left(\boldsymbol{\eta}_{(\mathrm{c})} / \boldsymbol{\eta}_{(0)}\right)$ Given in Brackets $\left(\boldsymbol{\eta}_{(0)}=\right.$ Viscosity in the Pure Solvent)

$\begin{array}{cll}\text { concentration/wt \% } & \eta \text { in EmimAc/Pa.s } & \eta \text { in BmimAc/Pa.s } \\ 0 & 0.162^{49} & 0.485^{49} \\ 0.5 & 0.169^{6} \text { (1.05 times) } & 0.640 \text { (1.32 times }) \\ 1 & 0.369^{6}(2.28 \text { times }) & 1.19(2.45 \text { times })\end{array}$

1.0 wt \%, A-cell/EmimAc was reported to have $\eta$ values of approximately 1.05 and 2.28 times larger compared to those of the pure solvent, ${ }^{6}$ while $A$-cell/BmimAc has $\eta$ values of approximately 1.32 and 2.45 times larger, for the same concentrations. Therefore, the effect of cellulose on the solvent viscosity appears to be relatively similar for the two types of IL. This will be further investigated through comparing the overlap concentrations and the intrinsic viscosities of $A$-cell in BmimAc and EmimAc.

Dilute and Semi-dilute Regimes. The concentration dependence of the zero-shear rate viscosity at $25{ }^{\circ} \mathrm{C}$ is given in Figure $2 \mathrm{a}$ for $A$-cell/BmimAc solutions. A linear region was observed for concentrations up to ca. 1 wt $\%$ for A-cell/ BmimAc solutions with an exponent of 1.5 for conc. > 1 wt \%. The former appears as a curved line, and the latter appears as a straight line in Figure 2a, since the data are plotted on a logarithmic scale. This is lower than exponents of $3.08^{6}$ and $2.4^{15}$ reported for MCC in EmimAc at $25{ }^{\circ} \mathrm{C}$, which may be due to the lack of data points at higher cellulose concentrations in this instance (i.e., not $>4 \mathrm{wt} \%$ ).

The specific viscosity $\left(\eta_{\text {sp }}\right)$ was used, so as to normalize out the effects of the pure solvent viscosity, ${ }^{21}$ to predict $c^{*}$ and $c_{\mathrm{e}}$ at $25{ }^{\circ} \mathrm{C}$ for $A$-cell in BmimAc (Figure 2b). Concentration was converted from wt $\%$ into $\mathrm{mL} \mathrm{g}^{-1}$, assuming that the density of
BmimAc remains constant over the concentration range ( $\rho=$ $1.05 \mathrm{~g} \mathrm{~mL}^{-1}$ ).

Three regions can generally be identified corresponding to the dilute, semi-dilute unentangled, and semi-dilute entangled regimes. Each region can be described by a power law dependency

$$
\eta_{\mathrm{sp}}=k c^{n}
$$

where $k$ is a constant and $n$ gives the power law for each region. The scaling prediction for neutral polymers in solvent estimates power law dependencies of 1,2 , and $14 / 3(\theta$ solvents) and 1, 1.3, and 3.9 (good solvents), for the dilute, semi-dilute unentangled, and semi-dilute entangled regions, respectively. ${ }^{17}$ Since a linear dependence in the dilute regime is predicted for both types of solvent, the first term of the equation was fixed as $n=1$, while the other two $n$ values, corresponding to the two semi-dilute regimes, were fitted to experimental data. At $25{ }^{\circ} \mathrm{C}$, just two exponents could be determined over the concentration range $0-4 \mathrm{wt} \%$, since 4.0 wt $\%$ appeared to be the only concentration at which $A$-cell/ BmimAc fell within the semi-dilute entangled regime (i.e., above $c_{\mathrm{e}}$ ). Power laws of $n=1$ and 1.9 were obtained, corresponding to the dilute and semi-dilute unentangled regimes (Figure $2 b$ ). These values are close to the scaling predictions for a $\theta$-solvent, which has been reported previously for cellulose in EmimAc. ${ }^{15,50}$

$c^{*}$ was estimated for A-cell/BmimAc solutions by extrapolating fits for the semi-dilute unentangled regime to $\eta_{\mathrm{sp}}=1 .^{51} c_{\mathrm{e}}$ values were defined as a change in the gradient from $\eta_{\mathrm{sp}}$ versus $c$ plots, observed by the eye (Figure $2 \mathrm{~b}$ ). It is worth noting that the cellulose source is expected to be relatively polydisperse, and therefore, transitions between the different regimes are more likely to be defined by a concentration range rather than by a specific value. ${ }^{51} c^{*}$ and $c_{\mathrm{e}}$ at $25{ }^{\circ} \mathrm{C}$ were found to be 0.77 and $3.4 \mathrm{wt} \%$, respectively, which is in agreement with the approximation $c_{\mathrm{e}} \approx 3$ to $5 \times c^{*} .^{17,21,40,45}$ The value of $c^{*}$ for $A$ cell in BmimAc is slightly lower than previously reported values for $A$-cell in EmimAc, ${ }^{6,16}$ suggesting that the polymer chains may overlap at a lower concentration in BmimAc relative to EmimAc.

Intrinsic Viscosity. The intrinsic viscosity $([\eta])$ gives information about the size of a polymer in a solution and thermodynamic quality of the solvent. $[\eta]$ is a measure of the hydrodynamic volume of polymer coils; $1 /[\eta]$ gives an approximate value for $c^{*}$ and can be compared to the values obtained from the power law fits. ${ }^{52}$ Traditionally, a capillary Ubbelohde viscometer is used for the determination of $[\eta]$, where solution and solvent flow times are measured, and the 

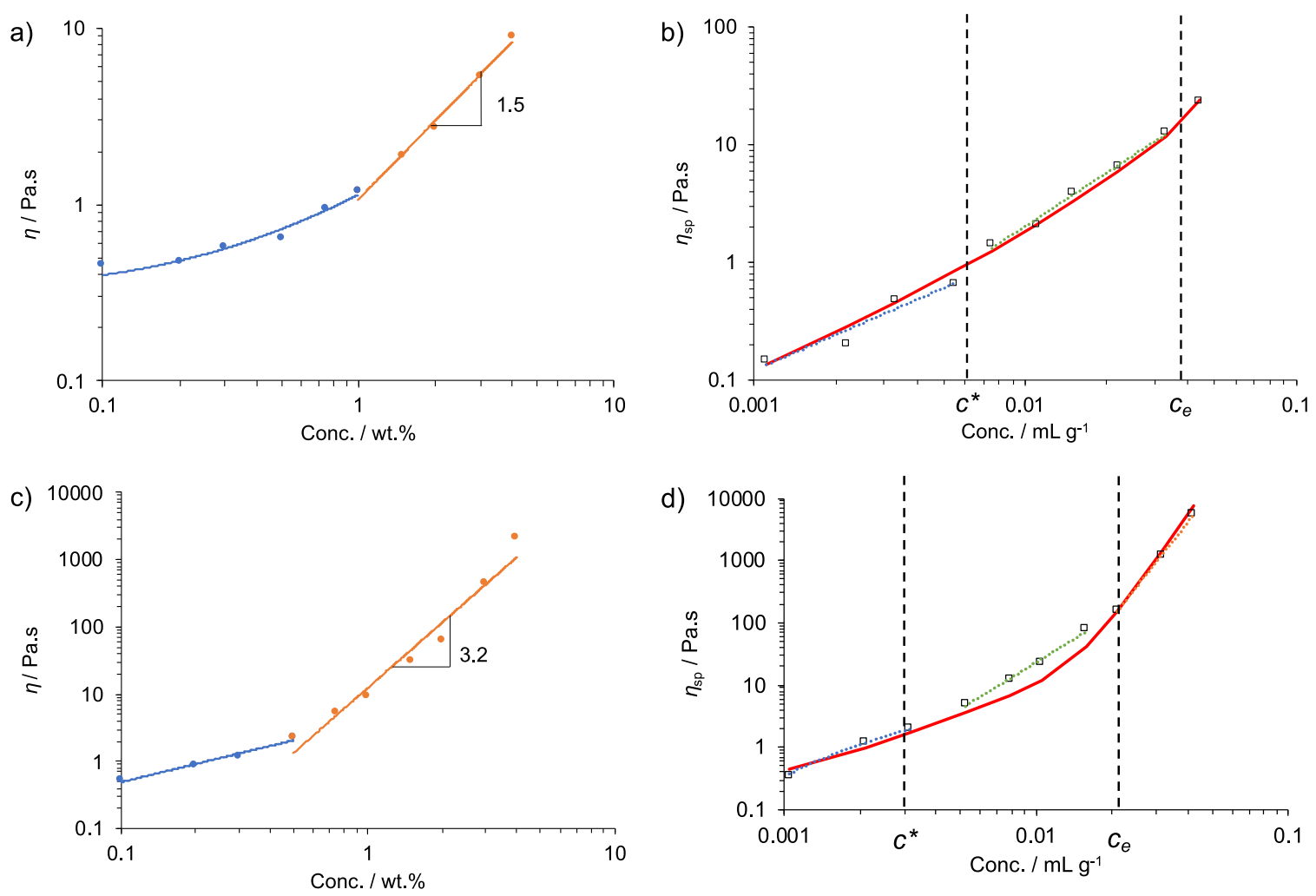

Figure 2. $\eta$ as a function of $A$-cell (a) and $V$-cell (c) concentration in BmimAc $\left(25^{\circ} \mathrm{C}\right)$, showing the linear region (blue) and the exponential region (orange); specific viscosity $\left(\eta_{\text {sp }}\right)$ as a function of $A$-cell $(\mathrm{b})$ and $V$-cell $(\mathrm{d})$ concentration in BmimAc $\left(25^{\circ} \mathrm{C}\right)$, showing the estimated overlap $\left(c^{*}\right)$ and entanglement $\left(c_{\mathrm{e}}\right)$ concentrations. The red line gives the best fit to eq 4 ; the blue, green, and orange dashed lines give the dilute, semidilute unentangled, and semi-dilute entangled regions, respectively.

relative viscosity $\left(\eta_{\text {rel }}\right)$ is analyzed as a function of concentration. However, this approach is problematic for IL solutions due to the high viscosity and hygroscopicity of the solvent.

A method outlined by Kulicke et al. is preferred in this instance, taking viscosity values over a large concentration range and relating $\eta_{\mathrm{sp}}$ and $[\eta]$ in the following manner ${ }^{16,19}$

$$
\eta_{\mathrm{sp}}=\sum_{k=1}^{n} A_{\mathrm{k}}(c[\eta])^{k}
$$

where $A_{\mathrm{k}}$ is a constant and $c$ is cellulose concentration.

The Huggins equation gives a truncated version of this when all parameters have exponents higher than 2, as described by Kulicke and Kniewske, ${ }^{19}$ and is defined as follows

$$
\eta_{\mathrm{sp}}=c[\eta]+K_{\mathrm{H}}(c[\eta])^{2}+B(c[\eta])^{\mathrm{m}}
$$

Here, $K_{\mathrm{H}}$ is the Huggins constant and $B$ and $m$ are constants. The Huggins constant has not yet been found for BmimAc, to the best of our knowledge. As a first approximation, $K_{\mathrm{H}}$ was taken to be 0.5 , since the exponent $\alpha$ in the Mark-Kuhn equation was $0.4<\alpha<0.6$ for EmimAc (between 0 and 100 ${ }^{\circ} \mathrm{C}$ ), and similarly, it has been shown that EmimAc is close to a $\theta$-solvent for cellulose at room temperature. ${ }^{15}$

A plot of $\log \left(\eta_{\mathrm{sp}}\right)$ versus $\log (c[\eta])$ for $A$-cell/BmimAc solutions at $25^{\circ} \mathrm{C}$ was used to deduce values for $B,[\eta]$, and $m$, approximated by the best fit of eq 4 to the experimental data (Figure S3). An estimation of $[\eta]$ was initially made by calculating $\eta_{\mathrm{sp}} / c$ and $\ln \left(\eta_{\mathrm{rel}}\right) / c$, in order to assess the accuracy of the obtained $[\eta]$ value from the equation and hence the quality of the fit. ${ }^{53}$
At $25{ }^{\circ} \mathrm{C},[\eta]=116 \mathrm{~mL} \mathrm{~g}^{-1}$ for $A$-cell/BmimAc solutions, while $B$ and $m$ were within the range $0.021-6.4 \times 10^{-5}$ and $4.5-7$, respectively, which are very close to values previously reported for $A$-cell/EmimAc $\left([\eta]=112 \mathrm{~mL} \mathrm{~g}^{-16}\right.$ and $[\eta]=$ ca. 100 to $\left.110 \mathrm{~mL} \mathrm{~g}^{-116}\right)$. This suggests that both the thermodynamic quality of the solvent and the hydrodynamic volume of the dissolved cellulose molecules are almost identical in BmimAc and EmimAc and that therefore, the anion has a greater influence on cellulose dissolution compared to the cation. This is in agreement with recent work by Brehm et al., who reported that the cellulose-anion interactions are significantly stronger than cellulose-cation interactions in ILs, and hence, the former contribute much more significantly to the total potential energy of cellulose dissolution. ${ }^{54}$ Thus, ILs with common anions are expected to display very similar macroscopic solution properties, when cellulose is dissolved.

Using the assumption $c^{*}=1 /[\eta]$ and the abovementioned value for $[\eta]$ gives $c^{*}=8.62 \times 10^{-3} \mathrm{~g} \mathrm{~mL}^{-1}$ (equivalent to 0.82 wt $\%$ ) for $A$-cell/BmimAc, which is in good agreement with the value of $0.77 \mathrm{wt} \%$ found in the section given above ("Dilute and Semi-dilute Regimes").

Rheological Properties of $\boldsymbol{V}$-Cell/BmimAc. The macroscopic properties of a different kind of cellulose $(V$-cell $)$ in BmimAc were also studied and compared to those of $A$-cell. We have recently published work on $V$-cell/BmimAc solutions and their coagulation to produce cellulose microgels, ${ }^{55}$ which have a wealth of potential applications in the food, cosmetic, and medical industries. Therefore, this study of the $V$-cell/ BmimAc solution properties was motivated by the need to understand the state of the dissolved cellulose before subsequent microgel fabrication. 


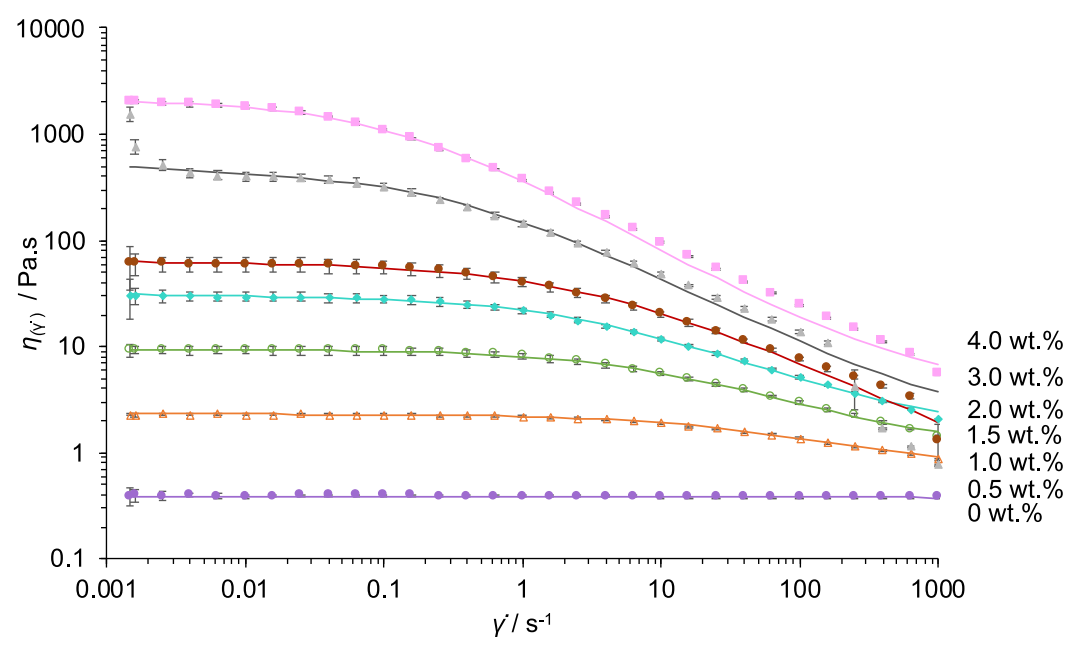

Figure 3. Flow curves for $0-4$ wt $\% V$-cell/BmimAc, showing the logarithmic plot of viscosity v shear rate at $25^{\circ} \mathrm{C}$. (Purple closed circle $=0$ wt $\%$; orange open triangle $=0.5 \mathrm{wt} \%$; green open circle $=1.0 \mathrm{wt} \%$; cyan closed diamond $=1.5 \mathrm{wt} \%$; red closed circle $=2.0 \mathrm{wt} \%$; gray closed triangle $=$ $3.0 \mathrm{wt} \%$; and pink closed square $=4.0 \mathrm{wt} \%$ ). Fits to the Cross model (eq 1) are given by the solid lines in the corresponding colors. Error bars are all shown, but some may be hidden by the symbol.

Figures 3 and $\mathrm{S} 1 \mathrm{~b}$ give the flow curves for $V$-cell/BmimAc solutions (0-4 wt \%), and the low-shear rate and shear thinning behavior described in Figure 1 is given in the Supporting Information, for dilute solutions (Figure S4). In contrast to $A$-cell/BmimAc, low shear rate and shear thinning was observed up to concentrations of ca. $0.3 \mathrm{wt} \% \mathrm{~V}$-cell/ BmimAc, with 0 and 0.2 wt \% displaying the most significant shear thinning between $\dot{\gamma}=0.001$ and $0.01 \mathrm{~s}^{-1}$. This suggests that BmimAc "clusters" were broken up with smaller amounts of dissolved $V$-cell compared to $A$-cell and that two "stages" of cluster formation may occur at 0 and 0.3 wt \%, (see the "Stokes-Einstein Analysis of V-cell/BmimAc Solutions" given below). Furthermore, $V$-cell/BmimAc solutions were found to be much more viscous with $\eta$ values of up to approximately 220 times larger $(c=4.0 \mathrm{wt} \%)$, compared to $A$-cell/BmimAc. Both of these observations suggest that $V$-cell has a much larger DP compared to $A$-cell, and therefore, the larger polymer chains have a greater influence on the IL viscosity at much lower concentrations. The DP of $V$-cell will be estimated in the following section, using the intrinsic viscosity.

The concentration dependences of $\eta$ and $\eta_{\mathrm{sp}}$ are given in Figure $2 c, d$, respectively, and once again, the data are shown on a logarithmic scale. An exponent of over twice the value of $A$-cell was observed for the non-linear region, and all three regimes (dilute, semi-dilute unentangled, and semi-dilute entangled) seemed to be present over the concentration range studied. The power laws (fitted to eq 2) for the three regions were $1,2.2$, and 4.4 , which are again close to the scaling predictions for $\theta$-solvents outlined in the section "Dilute and Semi-dilute Regimes". $c^{*}$ was estimated to be 0.20 wt $\%$ at $25^{\circ} \mathrm{C}$, which is over three times smaller than $c^{*}$ for $A$ cell/BmimAc, suggesting that $V$-cell chains begin to overlap at much lower concentrations and again indicating a significantly larger DP. $c_{\mathrm{e}}$ was estimated at $2.0 \mathrm{wt} \%$, which is not within the prediction $c_{\mathrm{e}} \approx 3-5 c^{*}$, confirming that less overlap is required to cause entanglement. This might in part be explained again by the chain inflexibility of polysaccharides, which is evidently more significant for cellulose with a larger DP. ${ }^{22,24}$

Considering the abovementioned observations, it follows that $[\eta]$ should be larger for $V$-cell/BmimAc compared to $A$ cell/BmimAc solutions, at a given temperature. As expected, a value of $[\eta]=350 \mathrm{~mL} \mathrm{~g}^{-1}$ was obtained for $V$-cell at $25^{\circ} \mathrm{C}$, which is approximately three times larger than $A$-cell (obtained by fitting to eq 4, Figure S5). $1 /[\eta]$ gives an estimated value of $c^{*}=0.27 \mathrm{wt} \%$, which is remarkably close to the value predicted above (by extrapolation to $\eta_{\text {sp }}=1$ ). The DP of $V$-cell was estimated from $[\eta]$ using the simple relationship given below $^{45}$

$$
[\eta] \approx 0.42 \mathrm{DP}
$$

giving a value of $\mathrm{DP} \approx 833$, and therefore, $M \approx 135,000$ for $V$ cell. This DP is over 4.5 times larger than the DP of $A$-cell (DP $=180),{ }^{25}$ and therefore, the higher viscosities observed for $V$ cell/BmimAc solutions are clearly due to the significantly larger polymer chain size.

Table 3 gives a comparison between different types of cellulose in different ILs and their intrinsic viscosities.

Table 3. Intrinsic Viscosity Values for Cellulose-IL Systems with Varying DPs

\begin{tabular}{llll}
\multicolumn{1}{c}{ type of cellulose (DP) } & \multicolumn{1}{c}{ solvent } & {$[\eta] / \mathrm{mL} \mathrm{g}^{-1}$} & refs \\
$\begin{array}{l}\text { Vitacel L 00 "V-cell" (ca. 730- } \\
\text { 830) }\end{array}$ & BmimAc & 350 & \\
Avicel MCC "A-cell" (180) & BmimAc & 116 & \\
Avicel MCC (180) & EmimAc & ca. 110 & 16 \\
MCC (235) & EmimAc & 112 & 6 \\
cellulose pulp (860) & EmimAc & 188 & 15 \\
cellulose (850) & EmimCl/DMSO & 236 & 17 \\
dissolving pulp cellulose (650) & AmimCl & 288.2 & 40 \\
$\alpha$-cellulose (C8002, ca. 850) & BmimCl & 357 & 45 \\
\hline
\end{tabular}

Interestingly, while $A$-cell gave an almost identical value of $[\eta]$ in both EmimAc and BmimAc, $V$-cell gives a value of almost two times as large in BmimAc when compared to cellulose pulp in EmimAc, which is expected to have a similar DP (as predicted by eq 5). This suggests that there may be more significant differences observable between EmimAc and BmimAc when cellulose with a larger DP is dissolved. While cellulose-anion interactions are expected to be more important than cellulose-cation interactions in ILs, ${ }^{54}$ possibly the contribution of the cation may become more significant in BmimAc compared to EmimAc. $[\eta]$ is more comparable 
between $V$-cell/BmimAc and $\alpha$-cellulose/BmimCl solutions, which have the same cation, suggesting that cellulose-cation interactions may be more important for dissolution of larger DP cellulose. Further studies of the same cellulose type with a larger DP in BmimAc and EmimAc separately are required to make a more direct comparison between the two solvents.

Effect of Temperature on Macroscopic Properties of $V$-Cell/BmimAc and Activation Energies. The effect of temperature $(T)$ on the rheological properties of $V$-cell/ BmimAc solutions was investigated at various concentrations. Figure 4 gives $\ln (\eta)$ as a function of $1 / T$ for $V$-cell/BmimAc

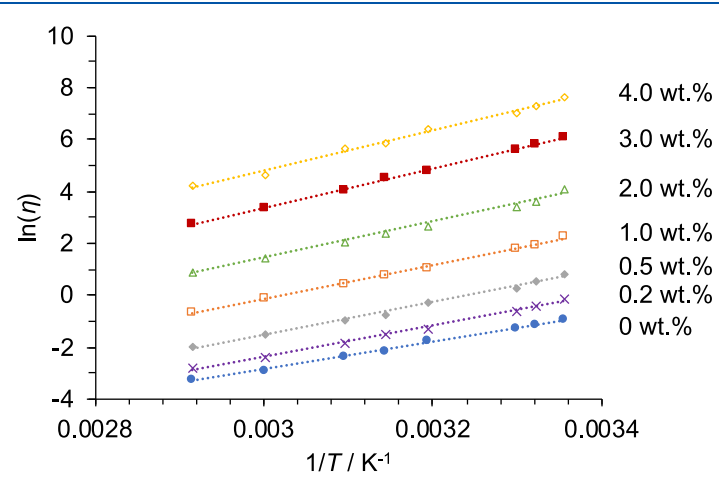

Figure 4. $\ln (\eta)$ as a function of $1 / T\left(25\right.$ to $\left.70{ }^{\circ} \mathrm{C}\right)$ for $0-4$ wt $\% V$ cell in BmimAc, obtained from the Cross model (blue closed circle $=$ $0 \mathrm{wt} \%$; purple cross $=0.2 \mathrm{wt} \%$; gray closed diamond $=0.5 \mathrm{wt} \%$; orange open square $=1.0 \mathrm{wt} \%$; green open triangle $=2.0 \mathrm{wt} \%$; red closed square $=3.0 \mathrm{wt} \%$; and yellow open diamond $=4.0 \mathrm{wt} \%)$. The straight lines give the Arrhenius analysis (eq 6).

solutions (0-4 wt \%), showing that the viscosity decreases as temperature increases (as expected for classical polymer solutions). Data for some of the dilute solutions have been omitted to make the figure clear, and the full data set can be found in the Supporting Information (Figure S6).

The viscosity-temperature dependence for $V$-cell/BmimAc solutions was further analyzed using the following Arrheniustype equation ${ }^{50}$

$$
\ln \eta=\ln \eta_{0}+\frac{E_{\mathrm{a}, \eta}}{\mathrm{RT}}
$$

where $\eta_{0}$ represents the pre-exponential factor, $E_{\mathrm{a}, \eta}$ is the activation energy for flow to occur, and $R$ is the universal gas constant. $E_{\mathrm{a}, \eta}$ can be deduced from the slope of $\ln (\eta)$ versus inverse temperature, if the dependence is linear.

Arrhenius plots for various concentrations of $V$-cell/ BmimAc are given in Figure 4, with linear fitting of each set of experimental data to deduce $E_{\mathrm{a}, \eta}$. Activation energies over the concentration range $0-4$ wt $\%$ and $R^{2}$ values corresponding to each linear fit are supplied in the Supporting Information (Table S3). An increase in $E_{\mathrm{a}, \eta}$ with $V$-cell concentration is observed, as depicted in Figure 5, which is due to an increase in the barrier for viscous flow in the bulk solution. $E_{\mathrm{a}, \eta}$ therefore gives a macroscopic parameter, which increases as the volume of cellulose-IL interactions increases. Surprisingly, a dip in the value of $E_{\mathrm{a}, \eta}$ is observed at $2.0 \mathrm{wt} \%$ (Table S3), around the estimated value of $c_{\mathrm{e}}$, which is most likely due to a poor fit to eq 6 for the preceding data point (1.5 wt $\% V$-cell/BmimAc). The relationship between $\ln (\eta)$ and inverse temperature for MCC-EmimAc solutions has been approximated by a concave dependence elsewhere. ${ }^{50}$ However, $E_{\mathrm{a}, \eta}$ is observed to increase with cellulose concentration within

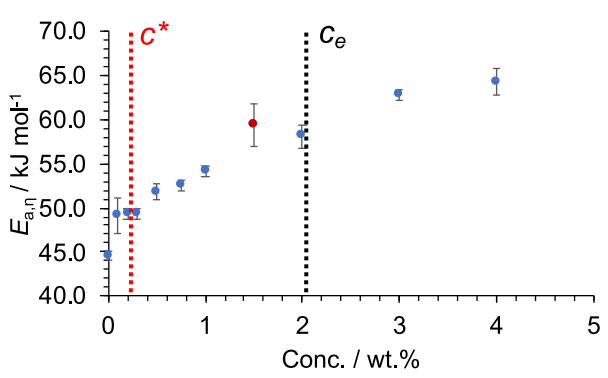

Figure 5. Plot of activation energies $\left(E_{a, \eta}\right)$ for flow, as deduced from eq 6, for $V$-cell dissolved in BmimAc at various concentrations of cellulose (conc. $=0-4.0 \mathrm{wt} \%$ ). Estimated values of $c^{*}$ and $c_{\mathrm{e}}$ at $25{ }^{\circ} \mathrm{C}$ are shown in red and black, respectively, and $E_{\mathrm{a}, \eta}$ for conc. $=1.5 \mathrm{wt} \%$ is represented in red, to signify a linear fit to eq 6 with $R^{2}<0.99$. Error bars were calculated based on the fit to eq 6 , and therefore, the uncertainty in determining the gradient and subsequently $E_{a, \eta}$ from the data. \% errors are listed in Table S3.

the error margins calculated, and in this instance, the Arrhenius approach was considered to give adequate accuracy.

It was observed that the onset of shear thinning occurs at higher shear rates as the temperature is increased, as illustrated by a plot of $1 / \mathrm{C}$ (from eq 1 ) versus $\mathrm{T}$ (Figure S7). $c^{*}$ and $c_{\mathrm{e}}$ were found to increase with $T$ (Supporting Information, Table S2 and Figure S8), while the exponent value in the non-linear region decreased correspondingly, suggesting that as the temperature increases, polymer chains overlap at a higher concentration. To confirm this, $[\eta]$ was found to decrease with $T$ (Figure 6, obtained from $\eta_{\text {sp }}$ vs concentration plots at 25-70

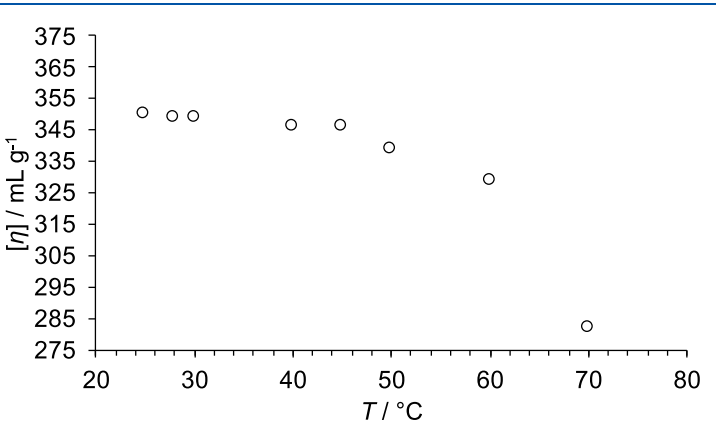

Figure 6. Intrinsic viscosity $([\eta])$ as a function of temperature for $V$ cell dissolved in BmimAc.

${ }^{\circ} \mathrm{C}$, Figure S9), and therefore, a decrease in solvent thermodynamic quality and polymer chain size is observed, which has been previously reported for various cellulose-IL solutions. $^{16,50}$

FFC NMR Studies of V-Cell/BmimAc Solutions. While rheological analysis offers insights into bulk properties of solutions, self-diffusion coefficients $(D)$ obtained from NMR can be used to probe interactions on a local level. Therefore, using the two techniques, one can compare the macroscopic and microscopic environment experienced by solvent molecules. Since molecular tumbling is expected to correlate with viscosity, FFC NMR was selected as a technique in this instance to provide a comparison to the rheological analysis. Only $V$-cell/BmimAc solutions were analyzed via FFC-NMR since $c^{*}$ and $c_{\mathrm{e}}$ were within the concentration range $(0-4 \mathrm{wt}$ $\%)$ unlike for $A$-cell, which requires higher concentrations to be within the semi-dilute entanglement regime (see analysis discussed above). Therefore, the effect of entanglements on 


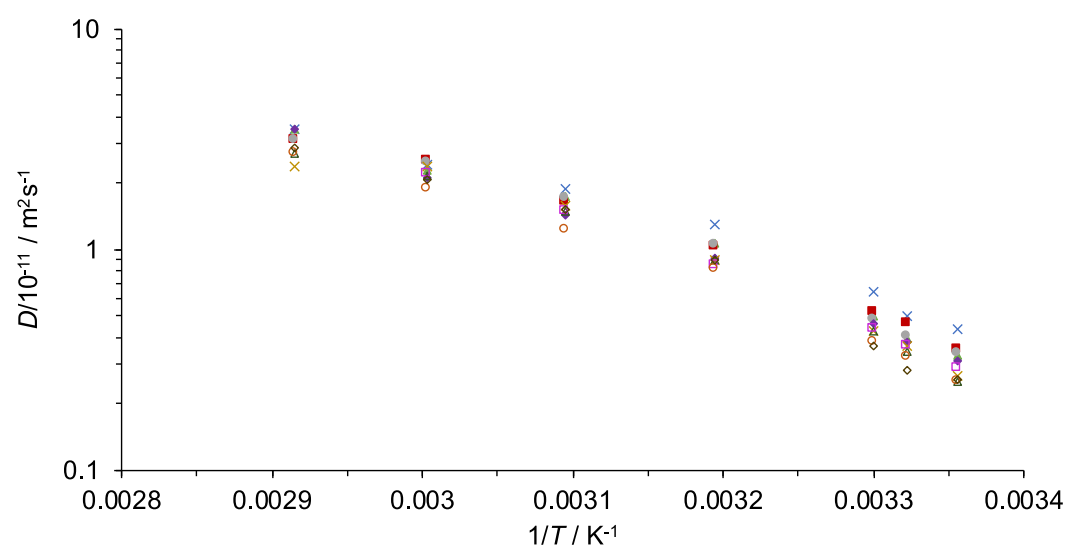

Figure 7. Logarithmic plot of self-diffusion coefficients $(D)$ as a function of the reciprocal temperature, for $V$-cell/BmimAc solutions: 0 wt \% (cross, blue); $0.1 \mathrm{wt} \%$ (closed triangle, light green); $0.2 \mathrm{wt} \%$ (closed square, red); $0.3 \mathrm{wt} \%$ (closed circle, light gray); $0.5 \mathrm{wt} \%$ (closed diamond, purple); $0.75 \mathrm{wt} \%$ (cross, dark yellow); $1.0 \mathrm{wt} \%$ (open triangle, dark green); $2.0 \mathrm{wt} \%$ (open square, pink); $3.0 \mathrm{wt} \%$ (open square, orange); and $4.0 \mathrm{wt} \%$ (open diamond, brown).

the macroscopic and microscopic properties of $V$-cell/BmimAc could be compared. The water content of each sample was determined using quantitative NMR and is given in the Supporting Information (Table S4). All of the $V$-cell/BmimAc solutions had an average water content of $0.44 \pm 0.24$ wt \%, except for the higher concentrations (3 and 4 wt \%). Therefore, these data have been included but have been highlighted (in red) in subsequent plots (Figures $8(\mathrm{~b})$ and $10(\mathrm{~b}))$ to signify that water may be significantly affecting the NMR signal.

Using the model-independent approach as first described by Kruk et al., ${ }^{34} D$ values can be obtained from the NMR dispersion (NMRD) curves characterized within the lowfrequency range $(0-10 \mathrm{MHz})$. The measured relaxation rate $\left(R_{1}\right)$ gives a sum of the intra- and intermolecular contributions to relaxation (eq $\mathrm{S} 1$ ). At sufficiently low frequencies, the translational contribution to $R_{1}$ is dominant, and therefore, $D$ can be determined in a model-independent way ${ }^{34}$

$$
R_{1}(\omega)=a-b \sqrt{\nu}
$$

where $a$ and $b$ are constants, given by the following equations

$$
\begin{aligned}
& a=R_{1}(0) \\
& b=N\left(\frac{\mu_{0}}{4 \pi} \gamma^{2} \hbar\right)^{2}\left(\frac{\sqrt{2}+8}{30}\right)\left(\frac{\pi}{D}\right)^{3 / 2}
\end{aligned}
$$

Full details of the theory can be found in the literature ${ }^{34}$ and are also provided in the Supporting Information.

$D$ values were determined for $0-4$ wt $\% V$-cell/BmimAc solutions using this approach over a range of temperatures, by fitting to eq S2 (Figure S10). ${ }^{38} \mathrm{D}$ values gave good agreement with literature values for cellulose/EmimAc systems in terms of the order of magnitude and the trend seen with increasing cellulose concentration (Figure S11). ${ }^{56}$ Therefore, this was deemed an accurate method for determining the translational motion of solvent molecules, BmimAc, with low concentrations of cellulose.

Ion size, shape, and strength of ion interactions all affect ion diffusivities. ${ }^{57}$ Figure 7 gives the dependence of $D$ on temperature, in a range of cellulose concentrations. As expected, for all $V$-cell/BmimAc solutions, $D$ decreases accordingly with decreasing temperature, corresponding to slower translational motion. At lower temperatures, $D$ also mostly decreases with increasing $V$-cell concentration, as generally observed for solvent molecules diffusing in polymer solutions. ${ }^{56}$ This can be explained in part by the corresponding power law increase in viscosity as a function of concentration, which drastically inhibits the diffusion of solvent molecules through the solution. As the temperature decreases, a wider range of values are obtained for $D$, and the effect of cellulose concentration on ion diffusivities becomes more enhanced. Therefore, the addition of cellulose appears to alter the ion diffusivities more significantly at lower temperatures, and interactions occurring on a local level should also be considered. Some further discussion of hydrodynamic interactions and their influence on ion diffusion can be found in the literature. ${ }^{56}$

Stokes-Einstein Analysis of V-Cell/BmimAc Solutions. Rheology and NMR experiments were compared using the Stokes-Einstein relationship, which correlates diffusivity and fluidity $(1 / \eta)$ as follows ${ }^{32}$

$$
D=\frac{k_{\mathrm{B}} T}{6 \pi f \eta r_{\mathrm{H}}}
$$

where $f$ is a correction factor (sometimes referred to as the microviscosity pre-factor) and $r_{\mathrm{H}}$ is the effective hydrodynamic radius of a molecule. Other variations of eq 10 may alternatively use a constant, $c$, which is linked to the correction factor as $c=6 f .^{58,59}$ For large molecules diffusing into smaller molecules, the hydrodynamic assumptions made using the Stokes-Einstein equation are valid, and therefore, $f=1$. $^{60}$ However, many small molecules show deviations from this value, and eq 10 may underpredict the value of $r_{\mathrm{H}}{ }^{61}$ as in the case of pure solvent where the diffusing molecule has the same size as the surrounding molecules. For ILs, the presence of strong intermolecular H-bonding networks and "dynamic heterogeneities" further invalidates the Stokes-Einstein relationship. $^{62}$ The latter describes the presence of spatial regions, which have significantly different relaxation times compared to the average relaxation time of the system, as studied for the IL 1-ethyl-3-methylimidazolium nitrate via molecular dynamics, ${ }^{63}$ where the formation of highly mobile ion clusters and short-lived cation-anion pairs is predicted.

An estimation of $r_{\mathrm{H}}$ can be determined from the following equation $^{32}$ 


$$
r_{\mathrm{H}}=\frac{1}{2}\left(\frac{M}{\rho N_{\mathrm{A}}}\right)^{1 / 3}
$$

where $M=$ molar mass; $\rho=$ density; and $N_{\mathrm{A}}=$ Avogadro's number. Values of $r_{\mathrm{H}}$ are 3.01 and $2.26 \AA$ for the $[\mathrm{Bmim}]^{+}$ cation and $[\mathrm{OAc}]^{-}$anion, respectively, which are close to previously published values of $3.3^{58}$ and $2.24 \AA .^{39}$ Since selfdiffusion coefficients were obtained via fitting of the FFC NMR data, the individual motion of the cation and anion cannot be distinguished. Therefore, $D$ describes the average motion across the ions, and an average value of $r_{\mathrm{H}}=2.64 \AA$ was used.

Figure $8 \mathrm{a}$ gives the relationship between $D$ obtained from FFC NMR and $T / \eta$ obtained from rheological experiments for
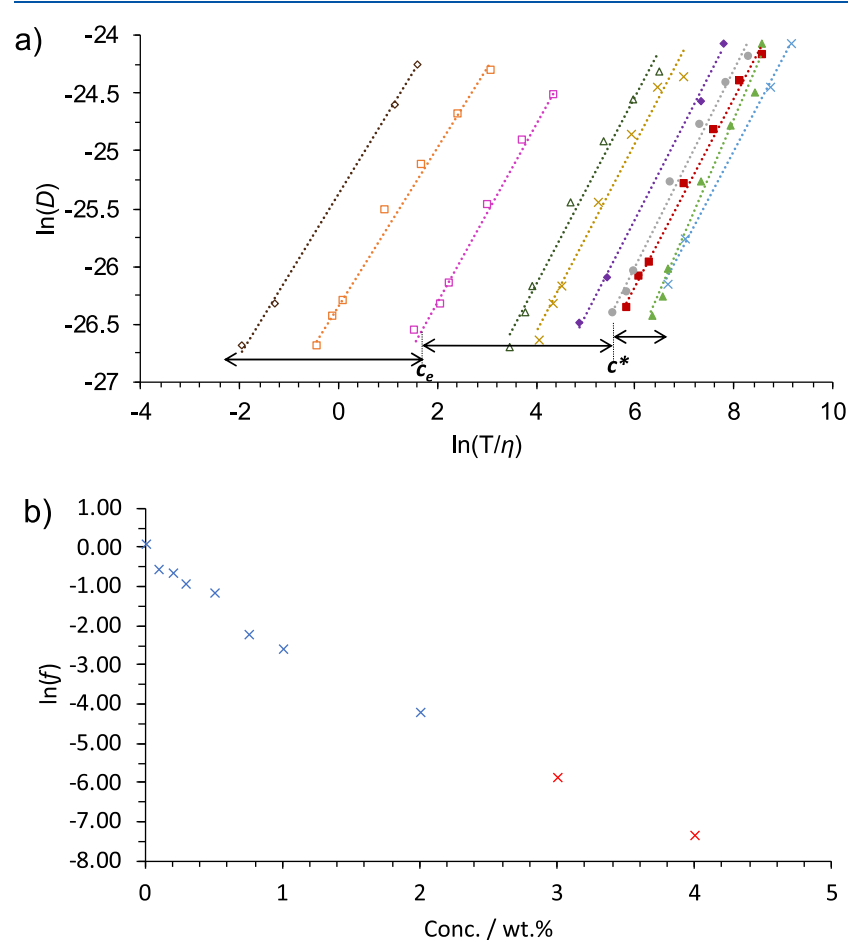

Figure 8. (a) Relationship between $\ln (D)$ and $\ln (T / \eta)$, as determined by FFC NMR and rheology, respectively: 0 wt \% (cross, blue); $0.1 \mathrm{wt}$ $\%$ (closed triangle, light green); $0.2 \mathrm{wt} \%$ (closed square, red); $0.3 \mathrm{wt}$ $\%$ (closed circle, light gray); 0.5 wt \% (closed diamond, purple); 0.75 wt \% (cross, dark yellow); $1.0 \mathrm{wt} \%$ (open triangle, dark green); $2.0 \mathrm{wt}$ $\%$ (open square, pink); $3.0 \mathrm{wt} \%$ (open square, orange); and $4.0 \mathrm{wt} \%$ (open diamond, brown). The dashed lines give linear fits, as in eq 10, and the dilute (green), semi-dilute unentangled (blue), and semidilute entangled (yellow) regions have been highlighted along with $c^{*}$ and $c_{\mathrm{e}} ;(\mathrm{b})$ correction factor $(f)$ shown as a function of cellulose concentration, as determined from eq 10. Data for 3.0 and $4.0 \mathrm{wt} \% \mathrm{~V}$ cell/BmimAc are shown in red, due to the higher water content in samples.

0-4 wt $\% V$-cell/BmimAc solutions, with straight-line fits given by the dashed lines. A linear dependence in the $\ln -\ln$ plot is observed with a gradient of ca. 0.9 for pure BmimAc, confirming the validity of the Stokes-Einstein relationship; however, the gradient decreases as the concentration of cellulose increases. Therefore, the macroscopic and microscopic properties are affected to differing extents by cellulose concentration. The macroscopic viscosity increases dramatically as the concentration of cellulose increases, which is in agreement with the behavior of MCC/EmimAc solutions; ${ }^{25}$ however, the microviscosity is much less affected. Such observations can be explained by the effect of entanglements, which have a significant impact on the macroscopic viscosity but almost no effect on the microviscosity and therefore $D$. This can be seen by an increase in the spacing of lines above $c^{*}$ (conc. $\approx 0.2 \mathrm{wt} \%$ ) and again above $c_{\mathrm{e}}$ (conc. $\approx 2.0 \mathrm{wt} \%$ ). For large polymers such as cellulose, large-scale effects such as these are observable using rheology but do not have an effect at the smaller length scales, and therefore, the local microviscosity as determined using NMR.

The correction factor $(f)$ was determined from the gradient of the linear plots of $D$ versus $T / \eta$, and $f$ is plotted as a function of cellulose concentration in Figure 8b. A value of $f=$ ca. 1 was obtained for the pure solvent and low-concentration cellulose solutions, suggesting that the Stokes-Einstein relationship is correctly relating the macroscopic to the microscopic environments. ${ }^{64}$ However, as cellulose is added, $f$ decreases in value as the Stokes-Einstein relationship starts to break down; the macroscopic viscosity is increasing much more rapidly than the microscopic viscosity. This is because the addition of cellulose causes overlap, entanglements, and large-scale structures, which dramatically increase the macroscopic viscosity. The value of $f$ drops most significantly between 0 and $0.1 \mathrm{wt} \%$, which is in agreement with observations from the rheological analysis, (where lowfrequency shear thinning behavior and therefore cluster formation were observed for the pure solution).

H-bonding has also been reported to increase the observed $f$ value. ${ }^{64}$ Various studies have shown that a pre-factor of $f=2 / 3$ is suitable for a variety of molecular liquids, ${ }^{58,59,65}$ and this value has been applied to the Stokes-Einstein analysis of EmimAc. ${ }^{39,64}$ However, we report that a value of $f=1$ may be more suitable for pure BmimAc, which may have a higher degree of cluster formation compared to EmimAc.

FFC NMR Relaxometry at a Single Frequency $(\nu=10$ $\mathrm{MHz}$ ). Further comparison of the macroscopic and microscopic environments can be made using relaxation times $\left(T_{1}\right)$ at a single frequency. $T_{1}$ was analyzed at $10 \mathrm{MHz}$ (low-field relaxometry) for each concentration of $V$-cell/BmimAc, over a range of temperatures. At $10 \mathrm{MHz}$, the $\mathrm{NMR}$ relaxation is dominated by rotational motion, giving complimentary information to the translational motion analyzed above. ${ }^{25}$

The logarithmic plot of $T_{1}$ as a function of inverse temperature is given in Figure 9. Analogous to $D, T_{1}$ decreases with decreasing temperature as molecular motion is slowed, and consequently, proton relaxation occurs more rapidly. Generally, $T_{1}$ was found to decrease with an increase in cellulose concentration, which can be once again explained by a decrease in molecular motion with an increase in polymersolvent interactions (Figure S12). This is in agreement with previous studies of $T_{1}$ as a function of $A$-cell concentration in EmimAc, ${ }^{25}$ where it was reported that $T_{1}$ is dependent on the number of $\mathrm{OH}$ groups on the cellulose "available" to bind to the IL molecules. However, the effect of $V$-cell concentration on $T_{1}$ was less pronounced than the effect on $D$. This is possibly due to the fact that relaxation is expected to be primarily governed by molecular tumbling at this frequency, while $D$ describes the effect of translational motion of molecules. Translational motion may be more significantly affected by concentration compared to tumbling, as a higher energy barrier for translational motion is required compared to rotational motion, and therefore, the increase in solventcellulose interactions will have a greater effect on the former. 


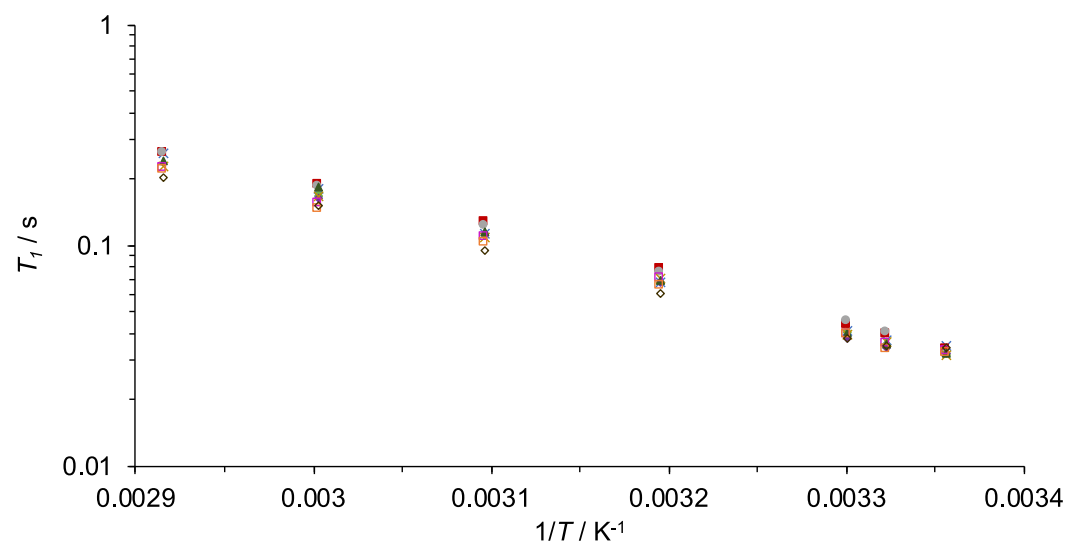

Figure 9. Logarithmic plot of relaxation time $\left(T_{1}\right)$ as a function of the reciprocal temperature for $V$-cell/BmimAc solutions: 0 wt $\%$ (cross, blue); $0.1 \mathrm{wt} \%$ (closed triangle, light green); $0.2 \mathrm{wt} \%$ (closed square, red); $0.3 \mathrm{wt} \%$ (closed circle, light gray); 0.5 wt \% (closed diamond, purple); 0.75 wt \% (cross, dark yellow); $1.0 \mathrm{wt} \%$ (open triangle, dark green); $2.0 \mathrm{wt} \%$ (open square, pink); $3.0 \mathrm{wt} \%$ (open square, orange); and $4.0 \mathrm{wt} \%$ (open diamond, brown).

Furthermore, $T_{1}$ values for $V$-cell/BmimAc solutions were approximately three times smaller than relaxation times reported for $A$-cell/EmimAc. ${ }^{25}$ This corresponds to the difference in solvent viscosities, where $\eta_{\mathrm{BmimAc}} \approx 3 \times \eta_{\mathrm{EmimAc}}$ (Table 2), since $1 / T_{1}$ is proportional to viscosity when rotational motion dominates the NMR relaxation mechanism (eqs 12 and 13).

Further valuable information on binding equilibria in cellulose-IL solutions may be gained from the intermolecular relaxation rate and the self-diffusion coefficient, by determination of Hertz's association parameter $(A), \quad(A=(1)$ $\left.T_{1, \text { inter }}\right) . D / c$, where $c$ is the number density of interacting spins). ${ }^{66}$ The concentration dependence of the $A$-parameter can be studied and used to describe the effect of dilution on solvent-solvent interactions in binary liquid mixtures. ${ }^{67}$ However, it is essential that the total relaxation rate is divided into $1 / T_{1, \text { inter }}$ and $1 / T_{1, \text { intra }}$ for which the most reliable method is isotopic dilution. ${ }^{66}$

Stokes-Einstein-Debye Analysis of V-Cell/BmimAc Solutions. The Stokes-Einstein equation can be extended to compare the rotational correlation time, $\tau_{\text {rot }}$ of a diffusing particle in a viscous medium, as described by Green et al., ${ }^{39}$ using the Stokes-Einstein-Debye equation

$$
\tau_{\text {rot }}=\frac{4}{3} \pi r_{\mathrm{H}}{ }^{3} f^{\prime} \frac{\eta}{k_{\mathrm{B}} T}
$$

where $\tau_{\text {rot }}$ gives the rotational correlation time and $f^{\prime}$ is a correction factor, similar to the term given in eq 10. Equation 12 can then be combined with the work of Bloembergen, Purcell, and Pound (BPP) to relate the molecular rotational correlation time and the NMR relaxation times $\left(T_{1}\right)$, in the high-temperature limit

$$
\frac{1}{T_{1}}=\frac{1}{T_{2}}=5 K \tau_{\text {rot }}
$$

where $K$, for spin $1 / 2$ nuclei, is described as follows

$$
K=\frac{3}{10} \gamma^{4} \hbar^{2}\left(\frac{\mu_{0}}{4 \pi}\right)^{2} \frac{1}{r_{\mathrm{eff}}{ }^{6}}
$$

where $\gamma$ is the gyromagnetic ratio for protons, $h$ is reduced Planck's constant, $\mu_{0}$ is the permeability of free space, and $r_{\text {eff }}$ is an effective inter proton distance. The two protons are assumed to be at a fixed distance and interacting via their magnetic dipolar fields. In this case, it is also assumed that $T_{1}=$ $T_{2}$ or, in other words, that rotational motion dominated the NMR relaxation. This is a reasonable assumption when working at a resonance frequency of $10 \mathrm{MHz}$ and within the high-temperature limit but may break down at frequencies below this. $^{64}$

Combining 12 and 13 gives the following relationship between $T_{1}$ and the viscosity ${ }^{64}$

$$
\frac{1}{T_{1}}=\left(\frac{20 \pi}{3} K r_{\mathrm{H}}^{3} f^{\prime}\right) \frac{\eta}{k_{\mathrm{B}} T}
$$

A value for $f^{\prime}$ can be determined for each concentration of $V$-cell/BmimAc from the gradient of Stokes-Einstein-Debye plots $\left(1 / T_{1}\right.$ vs $\left.\eta / T\right)$. As reported previously, an average value of $r_{\mathrm{H}}=2.64 \AA$ was used, and an estimation of $r_{\text {eff }}=2.59 \times$ $10^{-10} \mathrm{~m}$ was made (taking the molecular weight of BmimAc as $198.26 \mathrm{~g} \mathrm{~mol}^{-1}$, the density as $1.055 \mathrm{~g} \mathrm{~cm}^{-3}$, and the number of protons per molecule as 18 and assuming that protons are on a cubic lattice).

Figure 10a gives values of $T_{1}$ measured at a frequency of 10 $\mathrm{MHz}$ plotted as a function of $T / \eta$ for $0-4$ wt $\% V$-cell/ BmimAc, with straight-line fits given by the dashed lines. Once again, a linear dependence (as displayed in Figure 10a) was observed, and the cellulose concentration evidently has a greater effect on the macroscopic than the microscopic properties, indicated by an increase in the gradient of $T_{1}$ against $T / \eta$, with cellulose concentration. Therefore, the Stokes-Einstein-Debye relationship also breaks down as the polymer concentration increases.

Figure $10 \mathrm{~b}$ shows $\ln \left(f^{\prime}\right)$ as a function of cellulose concentration, obtained from the gradient of straight-line fits from eq 15. As with the diffusion, $f^{\prime}$ tends toward zero on an increase in cellulose concentration, revealing a far stronger dependence of macroscopic viscosity on cellulose concentration to that of the microviscosity. Since we are expecting to probe tumbling of ions at $10 \mathrm{MHz}$, it can be said that the rotational motion has a very similar dependence on concentration as the translational motion probed in the section given above, using the NMR dispersion curve. It is difficult to locate both $c^{*}$ and $c_{\mathrm{e}}$ from Figure $10 \mathrm{~b}$, again indicating that the effect of entanglements is greatly reduced at the microscopic level. 

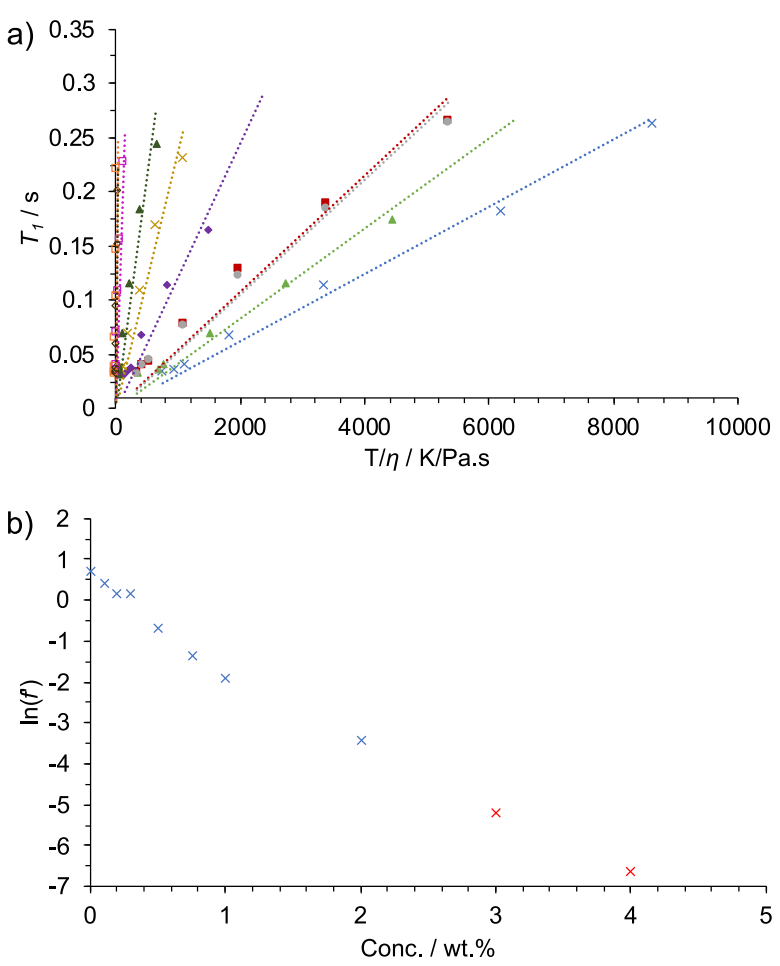

Figure 10. (a) Spin-lattice relaxation time $\left(T_{1}\right)$ as a function of temperature over zero-shear rate viscosity $\left(T / \eta_{0}\right)$ as determined by low-field NMR (10 MHz) and rheology, respectively: 0 wt \% (cross, blue); $0.1 \mathrm{wt} \%$ (closed triangle, light green); $0.2 \mathrm{wt} \%$ (closed square, red); 0.3 wt \% (closed circle, light gray); 0.5 wt \% (closed diamond, purple); 0.75 wt \% (cross, dark yellow); 1.0 wt \% (open triangle, dark green); 2.0 wt \% (open square, pink); $3.0 \mathrm{wt} \%$ (open square, orange); and $4.0 \mathrm{wt} \%$ (open diamond, brown). The dashed lines give linear fits, as in eq 15; (b) correction factor $\left(f^{\prime}\right)$ shown as a function of cellulose concentration, as determined from eq 15. Data for 3.0 and 4.0 wt $\% V$-cell/BmimAc are shown in red, due to the higher water content in samples. The remarkable similarity between Figures $10 \mathrm{~b}$ and $8 \mathrm{~b}$ indicates that the same microviscosity is determining both the translational and rotational motions of the ions.

Comparing the Activation Energies. Finally, in order to compare the results from self-diffusion, relaxometry, and rheological analysis, activation energies were calculated using the following Arrhenius-type equations

$$
\begin{aligned}
& \ln D=\ln D_{0}-\frac{E_{\mathrm{a}, \mathrm{D}}}{R T} \\
& \ln T_{1}=\ln T_{1,0}-\frac{E_{\mathrm{a}, T_{1}}}{R T}
\end{aligned}
$$

where $D_{0}$ and $T_{1,0}$ represent pre-exponential factors and $E_{\mathrm{a}, \mathrm{D}}$ and $E_{\mathrm{a}, \mathrm{T} 1}$ represent the activation energies of diffusion and rotation, respectively. As with $E_{\mathrm{a}, \eta}$, the gradient from linear fits of $\ln D$ or $\ln T_{1}$ versus inverse temperature was used to determine the activation energies for each process. $E_{\mathrm{a}, \mathrm{D}}$ and $E_{\mathrm{a}, \mathrm{T} 1}$ were both within the range of $30-40 \mathrm{~kJ} \mathrm{~mol}^{-1}$, which is about $10 \mathrm{~kJ} \mathrm{~mol}^{-1}$ lower than activation energies reported for MCC/EmimAc solutions. ${ }^{56} E_{a}$ values from viscosity, selfdiffusion, and relaxation are compared in Figure 11, where it is clear that $E_{\mathrm{a}, \eta}$ displays by far the greatest cellulose concentration dependence. This is in agreement with the Stokes-Einstein analysis, where the microviscosity was found to be less affected by concentration compared to the macroscopic viscosity. $E_{\mathrm{a}, \mathrm{D}}$ (self-diffusion) and $E_{\mathrm{a}, \eta}$ (viscosity) values obtained for pure BmimAc differed by ca. $10 \mathrm{~kJ} \mathrm{~mol}^{-1}$, whereas they were reported to be the same for pure EmimAc, ${ }^{56}$ which could again be attributed to more significant cluster formation in BmimAc (Figure 1).

\section{CONCLUSIONS}

Cellulose/BmimAc solutions with two different types of cellulose have been studied using rheology, where cellulose DP was found to have an effect on the macroscopic solution properties, $c^{*}, c_{\mathrm{e}}$, and $[\eta]$. The commercial cellulose $V$-cell (estimated DP $\simeq 730-830$ ) began to entangle at a much lower concentration compared to $A$-cell (DP $=180)$. Furthermore, $[\eta]$ of $V$-cell was approximately three times the value of $A$-cell, consistent with the larger DP and indicating a larger effective size of the polymer in solution. Interestingly, $A$-cell/BmimAc solutions displayed a very similar $[\eta]$ value to that of $A$-cell/ EmimAc solutions; ${ }^{16}$ however, $V$-cell gave a much lower $[\eta]$ value when compared to cellulose of a similar DP in EmimAc. ${ }^{15}$ This suggests that the IL cation has an effect on the dissolution of the cellulose and therefore may affect the macroscopic properties of the cellulose solutions.

The microscopic properties of $V$-cell/BmimAc solutions were then studied using FFC NMR and low-field relaxometry. Both $D$ and $T_{1}$ were found to decrease with increasing

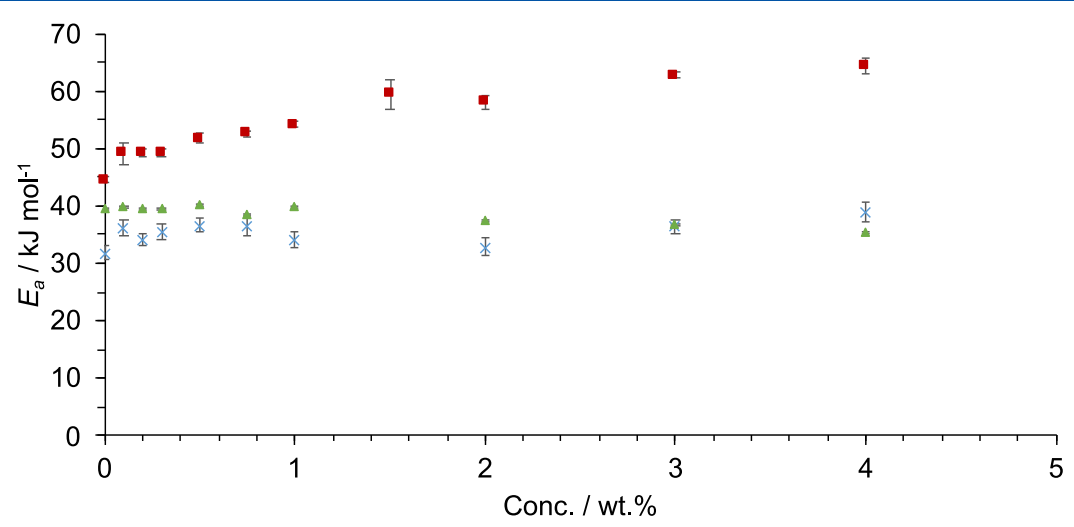

Figure 11. Activation energies for flow $\left(E_{\mathrm{a}, \eta}\right)$, translational $\left(E_{\mathrm{a}, \mathrm{D}}\right)$, and rotational $\left(E_{\mathrm{a}, \mathrm{T} 1}\right)$ motion as determined from the viscosities (rheology), selfdiffusion coefficients (FFC NMR), and relaxation times (low-field NMR, $10 \mathrm{MHz}$ ), respectively, as a function of cellulose concentration: $E_{\mathrm{a}, \eta}=$ red square; $E_{\mathrm{a}, \mathrm{D}}=$ blue cross; and $E_{\mathrm{a}, \mathrm{T} 1}=$ green triangle. Error bars were calculated based on the fit to eqs 6,16 , and 17 , therefore giving the uncertainty in determining the gradient and subsequently $E_{\mathrm{a}, \eta}, E_{\mathrm{a}, \mathrm{D}}$, and $E_{\mathrm{a}, \mathrm{T} 1}$ respectively. 
cellulose concentration, corresponding to both the increase observed in viscosity and an increase in the number of interactions between the solvent molecules and cellulose. Both of these factors result in a decrease in ion mobility as more polymer is added to the solution. Rheology and NMR could be directly compared using Stokes-Einstein and Stokes-Einstein-Debye analyses, where it was found that cellulose concentration has a much greater effect on the macroscopic viscosity compared to that on the microviscosity. This can be attributed to polymer entanglements, which affect much less significantly the microviscosity of cellulose/BmimAc solutions and therefore the short-range interactions, in agreement with the work previously published on A-cell/EmimAc solutions. ${ }^{25}$ Finally, an Arrhenius approach was used to obtain $E_{\mathrm{a}}$ values from rheological, FFC NMR, and low-field relaxometry analysis, corresponding to the respective energy barriers for flow, diffusional, and rotational motion. Consistent with the failure of the Stokes-Einstein relationship at higher cellulose concentrations, $E_{\mathrm{a}, \eta}$ was found to be greater than both $E_{\mathrm{a}, \mathrm{D}}$ and $E_{\mathrm{a}, \mathrm{T} 1}$ at all cellulose concentrations and displayed by far the greatest concentration dependence. This indicates that the energy barrier for flow (a bulk solution property) is affected much more significantly by polymer concentration than the energy barriers for rotation and diffusion (microscopic solution properties). This study provides further insights into the interactions occurring on a macroscopic and local level in cellulose-IL solutions, which is crucial to understand the properties of cellulose materials coagulated from cellulose-IL solutions.

\section{ASSOCIATED CONTENT}

\section{(s) Supporting Information}

The Supporting Information is available free of charge at https://pubs.acs.org/doi/10.1021/acs.jpcb.1c02848. Data can be found at https://doi.org/10.5518/978.

Vitacel powdered cellulose L 00 ( $V$-cell), information provided by the manufacturer (J. Rettenmaier \& Söhne $\mathrm{GmbH} \& \mathrm{Co}$. KG); FFC NMR relaxometry theory; flow curves for $0-4$ wt $\% A$-cell/BmimAc, showing the logarithmic plot of viscosity versus shear rate at $25^{\circ} \mathrm{C}$; low-frequency shear rate region for dilute solutions of $A$ cell/BmimAc (0-1 wt \%), showing the logarithmic plot of viscosity versus shear rate at $25{ }^{\circ} \mathrm{C}$; plot of $\log (\eta \mathrm{sp})$ versus $\log (C[\eta])$ for $A$-cell/BmimAc solutions at $25^{\circ} \mathrm{C}$; low-frequency shear rate region for dilute solutions of $V$ cell/BmimAc (0-0.3 wt \%), showing the logarithmic plot of viscosity versus shear rate at $25{ }^{\circ} \mathrm{C}$; plot of $\log \left(\eta_{\text {sp }}\right)$ versus $\log (c[\eta])$ for $V$-cell/BmimAc solutions at $25^{\circ} \mathrm{C}$; logarithmic plots of $\eta$ as a function of $1 / T$ (25$70{ }^{\circ} \mathrm{C}$ ) for all concentrations, $0-4$ wt \%, of V-cell in BmimAc; shear thinning behavior $(1 / C)$ as a function of temperature, for 1.0 and $2.0 \mathrm{wt} \% V$-cell in BmimAc; $c^{*}$, $c_{\mathrm{e}}$, and exponents for $V$-cell/BmimAc solution $(T=25-$ $\left.70{ }^{\circ} \mathrm{C}\right)$; estimated overlap concentration $\left(c^{*}\right.$, blue) and entanglement concentration $\left(c_{\mathrm{e}}\right.$, orange $)$ as a function of temperature for $V$-cell/BmimAc solutions; $\eta_{\mathrm{p}}$ as a function of $V$-cell concentration in BmimAc $(28-70$ ${ }^{\circ} \mathrm{C}$ ), with $c^{*}$ and $c_{\mathrm{e}}$ indicated by the dashed lines; activation energies for $V$-cell dissolved in BmimAc at various concentrations of cellulose (conc. $=0-4.0 \mathrm{wt}$ $\%)$; concentration of $\mathrm{V}$-cell/BmimAc solutions with their respective water contents ( $\mathrm{wt} \%$ ), as determined by high-field ${ }^{1} \mathrm{H}$ NMR (400 MHz); NMRD profiles of 0-4 wt $\% V$-cell/BmimAc at $28,30,40,50,60$, and $70{ }^{\circ} \mathrm{C}$; self-diffusion coefficients $(D)$ of $V$-cell/BmimAc solutions obtained from NMRD profiles, as a function of cellulose concentration; and relaxation times $\left(T_{1}\right)$ of $V$ cell/BmimAc solutions $(\nu=10 \mathrm{MHz})$, as a function of cellulose concentration (PDF)

\section{AUTHOR INFORMATION}

\section{Corresponding Author}

Michael E. Ries - School of Physics and Astronomy, University of Leeds, Leeds LS2 9JT, U.K.; 이이.org/0000-0002-

8050-3200; Email: M.E.Ries@leeds.ac.uk

\section{Authors}

Katherine S. Lefroy - School of Food Science and Nutrition, University of Leeds, Leeds LS2 9JT, U.K.

Brent S. Murray - School of Food Science and Nutrition, University of Leeds, Leeds LS2 9JT, U.K.

Complete contact information is available at:

https://pubs.acs.org/10.1021/acs.jpcb.1c02848

\section{Notes}

The authors declare no competing financial interest.

\section{ACKNOWLEDGMENTS}

The authors gratefully acknowledge the Engineering and Physical Sciences Research Council (EPSRC) funded Centre for Doctoral Training in Soft Matter and Functional Interfaces (SOFI), Grant Ref. no. EP/L015536/1, and Mondelez International (Reading, UK) for financial support.

\section{REFERENCES}

(1) Walden, P. Molecular Magnitude and Electrical Conductivity of Some Fused Salts. Bull. Acad. Imp. Sci. St.-Petersbourg 1914, 8, 405422.

(2) Takada, A.; Kadokawa, J.-i. Fabrication and Characterization of Polysaccharide Ion Gels with Ionic Liquids and Their Further Conversion into Value-Added Sustainable Materials. Biomolecules 2015, 5, 244-262.

(3) Xu, S.; Zhang, J.; He, A.; Li, J.; Zhang, H.; Han, C. C. Electrospinning of Native Cellulose from Nonvolatile Solvent System. Polymer 2008, 49, 2911-2917.

(4) Chua, E. T.; Brunner, M.; Atkin, R.; Eltanahy, E.; Thomas-Hall, S. R.; Schenk, P. M. The Ionic Liquid Cholinium Arginate Is an Efficient Solvent for Extracting High-Value Nannochloropsis Sp. Lipids. ACS Sustainable Chem. Eng. 2019, 7, 2538-2544.

(5) Lindman, B.; Karlström, G.; Stigsson, L. On the Mechanism of Dissolution of Cellulose. J. Mol. Liq. 2010, 156, 76-81.

(6) Tan, X.; Li, X.; Chen, L.; Xie, F. Solubility of Starch and Microcrystalline Cellulose in 1-Ethyl-3-Methylimidazolium Acetate Ionic Liquid and Solution Rheological Properties. Phys. Chem. Chem. Phys. 2016, 18, 27584-27593.

(7) Lefroy, K. S.; Murray, B. S.; Ries, M. E. Advances in the Use of Microgels as Emulsion Stabilisers and as a Strategy for Cellulose Functionalisation. Cellulose 2021, 28, 647-670.

(8) Pinkert, A.; Marsh, K. N.; Pang, S.; Staiger, M. P. Ionic Liquids and Their Interaction with Cellulose. Chem. Rev. 2009, 109, 67126728.

(9) Tang, S.; Baker, G. A.; Ravula, S.; Jones, J. E.; Zhao, H. PEGFunctionalized Ionic Liquids for Cellulose Dissolution and Saccharification. Green Chem. 2012, 14, 2922-2932.

(10) El Seoud, O. A.; Koschella, A.; Fidale, L. C.; Dorn, S.; Heinze, T. Applications of Ionic Liquids in Carbohydrate Chemistry: A Window of Opportunities. Biomacromolecules 2007, 8, 2629-2647. 
(11) Marks, C.; Mitsos, A.; Viell, J. Change of C(2)-HydrogenDeuterium Exchange in Mixtures of EMIMAc. J. Solution Chem. 2019, $48,1188-1205$.

(12) Hauru, L. K. J.; Hummel, M.; King, A. W. T.; Kilpeläinen, I.; Sixta, H. Role of Solvent Parameters in the Regeneration of Cellulose from Ionic Liquid Solutions. Biomacromolecules 2012, 13, 2896-2905.

(13) Verma, C.; Mishra, A.; Chauhan, S.; Verma, P.; Srivastava, V.; Quraishi, M. A.; Ebenso, E. E. Dissolution of Cellulose in Ionic Liquids and Their Mixed Cosolvents: A Review. Sustainable Chem. Pharm. 2019, 13, 100162.

(14) Wendler, F.; Todi, L.-N.; Meister, F. Thermostability of Imidazolium Ionic Liquids as Direct Solvents for Cellulose. Thermochim. Acta 2012, 528, 76-84.

(15) Haward, S. J.; Sharma, V.; Butts, C. P.; McKinley, G. H.; Rahatekar, S. S. Shear and Extensional Rheology of Cellulose/Ionic Liquid Solutions. Biomacromolecules 2012, 13, 1688-1699.

(16) Sescousse, R.; Le, K. A.; Ries, M. E.; Budtova, T. Viscosity of Cellulose-Imidazolium-Based Ionic Liquid Solutions. J. Phys. Chem. B 2010, 114, 7222-7228.

(17) Lu, F.; Wang, L.; Zhang, C.; Cheng, B.; Liu, R.; Huang, Y. Influence of Temperature on the Solution Rheology of Cellulose in 1Ethyl-3-Methylimidazolium Chloride/Dimethyl Sulfoxide. Cellulose 2015, 22, 3077-3087.

(18) Napso, S.; Rein, D. M.; Khalfin, R.; Kleinerman, O.; Cohen, Y. Cellulose Gel Dispersion: From Pure Hydrogel Suspensions to Encapsulated Oil-in-Water Emulsions. Colloids Surf., B 2016, 137, $70-76$.

(19) Kulicke, W.-M.; Kniewske, R. The Viscosity Dependence on Concentration, Molecular Weight and Shear Rate of Xanthan Solutions. Rheol. Acta 1984, 23, 75-83.

(20) Colby, R. H. Structure and Linear Viscoelasticity of Flexible Polymer Solutions: Comparison of Polyelectrolyte and Neutral Polymer Solutions. Rheol. Acta 2010, 49, 425-442.

(21) Lu, F.; Song, J.; Cheng, B.-W.; Ji, X.-J.; Wang, L.-J. Viscoelasticity and Rheology in the Regimes from Dilute to Concentrated in Cellulose 1-Ethyl-3-Methylimidazolium Acetate Solutions. Cellulose 2013, 20, 1343-1352.

(22) Lopez, C. G.; Voleske, L.; Richtering, W. Scaling Laws of Entangled Polysaccharides. Carbohydr. Polym. 2020, 234, 115886.

(23) Kraemer, E. O.; Lansig, W. D. The Molecular Weights of Cellulose and Cellulose Derivatives. J. Phys. Chem. 1935, 39, 153168.

(24) Horinaka, J.-i.; Chen, K.; Takigawa, T. Entanglement Properties of Carboxymethyl Cellulose and Related Polysaccharides. Rheol. Acta 2018, 57, 51-56.

(25) Ries, M. E.; Radhi, A.; Green, S. M.; Moffat, J.; Budtova, T. Microscopic and Macroscopic Properties of Carbohydrate Solutions in the Ionic Liquid 1-Ethyl-3-Methyl-Imidazolium Acetate. J. Phys. Chem. B 2018, 122, 8763-8771.

(26) Zhang, J.; Zhang, H.; Wu, J.; Zhang, J.; He, J.; Xiang, J. NMR Spectroscopic Studies of Cellobiose Solvation in EmimAc Aimed to Understand the Dissolution Mechanism of Cellulose in Ionic Liquids. Phys. Chem. Chem. Phys. 2010, 12, 1941-1947.

(27) Zhang, J.; Xu, L.; Yu, J.; Wu, J.; Zhang, X.; He, J.; Zhang, J. Understanding Cellulose Dissolution: Effect of the Cation and Anion Structure of Ionic Liquids on the Solubility of Cellulose. Sci. China: Chem. 2016, 59, 1421-1429.

(28) Remsing, R. C.; Swatloski, R. P.; Rogers, R. D.; Moyna, G. Mechanism of Cellulose Dissolution in the Ionic Liquid 1-n-Butyl-3Methylimidazolium Chloride: A $13 \mathrm{C}$ and 35/37Cl NMR Relaxation Study on Model Systems. Chem. Commun. 2006, 12, 1271-1273.

(29) Xu, A.; Wang, J.; Wang, H. Effects of Anionic Structure and Lithium Salts Addition on the Dissolution of Cellulose in 1-Butyl-3Methylimidazolium-Based Ionic Liquid Solvent Systems. Green Chem. 2010, 12, 268-275.

(30) Gentile, L.; Olsson, U. Cellulose-Solvent Interactions from Self-Diffusion NMR. Cellulose 2016, 23, 2753-2758.

(31) Youngs, T. G. A.; Holbrey, J. D.; Mullan, C. L.; Norman, S. E.; Lagunas, M. C.; D’Agostino, C.; Mantle, M. D.; Gladden, L. F.;
Bowron, D. T.; Hardacre, C. Neutron Diffraction, NMR and Molecular Dynamics Study of Glucose Dissolved in the Ionic Liquid 1-Ethyl-3-Methylimidazolium Acetate. Chem. Sci. 2011, 2, 15941605.

(32) Radhi, A.; Le, K. A.; Ries, M. E.; Budtova, T. Macroscopic and Microscopic Study of 1-Ethyl-3-Methyl-Imidazolium Acetate-DMSO Mixtures. J. Phys. Chem. B 2015, 119, 1633-1640.

(33) Rachocki, A.; Tritt-Goc, J. Novel Application of NMR Relaxometry in Studies of Diffusion in Virgin Rape Oil. Food Chem. 2014, 152, 94-99.

(34) Kruk, D.; Meier, R.; Rössler, E. A. Nuclear Magnetic Resonance Relaxometry as a Method of Measuring Translational Diffusion Coefficients in Liquids. Phys. Rev. E: Stat., Nonlinear, Soft Matter Phys. 2012, 85, 020201.

(35) Ordikhani Seyedlar, A.; Stapf, S.; Mattea, C. Dynamics of the Ionic Liquid 1-Butyl-3-Methylimidazolium Bis(Trifluoromethylsulphonyl)Imide Studied by Nuclear Magnetic Resonance Dispersion and Diffusion. Phys. Chem. Chem. Phys. 2015, 17, 1653-1659.

(36) Kaszyńska, J.; Rachocki, A.; Bielejewski, M.; Tritt-Goc, J. Influence of Cellulose Gel Matrix on BMIMCl Ionic Liquid Dynamics and Conductivity. Cellulose 2017, 24, 1641-1655.

(37) Rachocki, A.; Andrzejewska, E.; Dembna, A.; Tritt-Goc, J. Translational Dynamics of Ionic Liquid Imidazolium Cations at Solid/Liquid Interface in Gel Polymer Electrolyte. Eur. Polym. J. 2015, 71, 210-220.

(38) Kruk, D.; Meier, R.; Rachocki, A.; Korpała, A.; Singh, R. K.; Rössler, E. A. Determining Diffusion Coefficients of Ionic Liquids by Means of Field Cycling Nuclear Magnetic Resonance Relaxometry. J. Chem. Phys. 2014, 140, 244509.

(39) Green, S. M.; Ries, M. E.; Moffat, J.; Budtova, T. NMR and Rheological Study of Anion Size Influence on the Properties of Two Imidazolium-Based Ionic Liquids. Sci. Rep. 2017, 7, 8968.

(40) Kuang, Q.-L.; Zhao, J.-C.; Niu, Y.-H.; Zhang, J.; Wang, Z.-G. Celluloses in an Ionic Liquid: The Rheological Properties of the Solutions Spanning the Dilute and Semidilute Regimes. J. Phys. Chem. B 2008, 112, 10234-10240.

(41) Vitz, J.; Erdmenger, T.; Haensch, C.; Schubert, U. S. Extended Dissolution Studies of Cellulose in Imidazolium Based Ionic Liquids. Green Chem. 2009, 11, 417-442.

(42) Kosan, B.; Michels, C.; Meister, F. Dissolution and Forming of Cellulose with Ionic Liquids. Cellulose 2008, 15, 59-66.

(43) Hermanutz, F.; Gähr, F.; Uerdingen, E.; Meister, F.; Kosan, B. New Developments in Dissolving and Processing of Cellulose in Ionic Liquids. Macromol. Symp. 2008, 262, 23-27.

(44) Cross, M. M. Rheology of Non-Newtonian Fluids: A New Flow Equation for Pseudoplastic Systems. J. Colloid Sci. 1965, 20, 417-437.

(45) Chen, X.; Zhang, Y.; Wang, H.; Wang, S.-W.; Liang, S.; Colby, R. H. Solution Rheology of Cellulose in 1-Butyl-3-Methyl Imidazolium Chloride. J. Rheol. 2011, 55, 485-494.

(46) Cha, S.; Ao, M.; Sung, W.; Moon, B.; Ahlström, B.; Johansson, P.; Ouchi, Y.; Kim, D. Structures of Ionic Liquid-Water Mixtures Investigated by IR and NMR Spectroscopy. Phys. Chem. Chem. Phys. 2014, 16, 9591-9601.

(47) Wang, Q.; Yang, Y.; Chen, X.; Shao, Z. Investigation of Rheological Properties and Conformation of Silk Fibroin in the Solution of AmimCl. Biomacromolecules 2012, 13, 1875-1881.

(48) Chen, S.; Zhang, S.; Liu, X.; Wang, J.; Wang, J.; Dong, K.; Sun, J.; Xu, B. Ionic Liquid Clusters: Structure, Formation Mechanism, and Effect on the Behavior of Ionic Liquids. Phys. Chem. Chem. Phys. 2014, 16, 5893-5906.

(49) Fendt, S.; Padmanabhan, S.; Blanch, H. W.; Prausnitz, J. M. Viscosities of Acetate or Chloride-Based Ionic Liquids and Some of Their Mixtures with Water or Other Common Solvents. J. Chem. Eng. Data 2011, 56, 31-34.

(50) Gericke, M.; Schlufter, K.; Liebert, T.; Heinze, T.; Budtova, T. Rheological Properties of Cellulose/Ionic Liquid Solutions: From Dilute to Concentrated States. Biomacromolecules 2009, 10, 11881194. 
(51) Behra, J. S.; Mattsson, J.; Cayre, O. J.; Robles, E. S. J.; Tang, H.; Hunter, T. N. Characterization of Sodium Carboxymethyl Cellulose Aqueous Solutions to Support Complex Product Formulation: A Rheology and Light Scattering Study. ACS Appl. Polym. Mater. 2019, $1,344-358$.

(52) Lue, A.; Liu, Y.; Zhang, L.; Potthas, A. Light Scattering Study on the Dynamic Behaviour of Cellulose Inclusion Complex in LiOH/ Urea Aqueous Solution. Polymers 2011, 52, 3857-3864.

(53) Ren, Y.; Ellis, P. R.; Ross-Murphy, S. B.; Wang, Q.; Wood, P. J. Dilute and Semi-Dilute Solution Properties of $(1 \rightarrow 3),(1 \rightarrow 4)-\beta$-DGlucan, the Endosperm Cell Wall Polysaccharide of Oats (Avena Sativa L.). Carbohydr. Polym. 2003, 53, 401-408.

(54) Brehm, M.; Radicke, J.; Pulst, M.; Shaabani, F.; Sebastiani, D.; Kressler, J. Dissolving Cellulose in 1,2,3-Triazolium-and ImidazoliumBased Ionic Liquids with Aromatic Anions. Molecules 2020, 25, 3539.

(55) Lefroy, K. S.; Murray, B. S.; Ries, M. E.; Curwen, T. D. A Natural, Cellulose-Based Microgel for Water-in-Oil Emulsions. Food Hydrocolloids 2021, 113, 106408.

(56) Lovell, C. S.; Walker, A.; Damion, R. A.; Radhi, A.; Tanner, S. F.; Budtova, T.; Ries, M. E. Influence of Cellulose on Ion Diffusivity in 1-Ethyl-3-Methyl-Imidazolium Acetate Cellulose Solutions. Biomacromolecules 2010, 11, 2927-2935.

(57) Zhao, Y.; Gao, S.; Wang, J.; Tang, J. Aggregation of Ionic Liquids [Cnmim] $\mathrm{Br}(\mathrm{n}=4,6,8,10,12)$ in D2O: A NMR Study. J. Phys. Chem. B 2008, 112, 2031-2039.

(58) Tokuda, H.; Hayamizu, K.; Ishii, K.; Susan, M. A. B. H.; Watanabe, M. Physicochemical Properties and Structures of Room Temperature Ionic Liquids. 1. Variation of Anionic Species. J. Phys. Chem. B 2004, 108, 16593-16600.

(59) Mclaughlin, E. Viscosity and Self-Diffusion. Trans. Faraday Soc. 1959, 55, 28-38.

(60) Powell, R. E.; Roseveare, W. E.; Eyring, H. Diffusion, Thermal Conductivity, and Viscous Flow of Liquids. Ind. Eng. Chem. 1941, 33, 430-435.

(61) Antony, J. H.; Dölle, A.; Mertens, D.; Wasserscheid, P.; Carper, W. R.; Wahlbeck, P. G. 13C NMR Relaxation Rates in the Ionic Liquid 1-Methyl-3-Nonylimidazolium Hxafluorophosphate. J. Phys. Chem. A 2005, 109, 6676-6682.

(62) Köddermann, T.; Ludwig, R.; Paschek, D. On the Validity of Stokes-Einstein and Stokes-Einstein-Debye Relations in Ionic Liquids and Ionic-Liquid Mixtures. ChemPhysChem 2008, 9, 1851-1858.

(63) Del Pópolo, M. G.; Voth, G. A. On the Structure and Dynamics of Ionic Liquids. J. Phys. Chem. B 2004, 108, 1744-1752.

(64) Hall, C. A.; Le, K. A.; Rudaz, C.; Radhi, A.; Lovell, C. S.; Damion, R. A.; Budtova, T.; Ries, M. E. Macroscopic and Microscopic Study of 1-Ethyl-3-Methyl-Imidazolium Acetate-Water Mixtures. J. Phys. Chem. B 2012, 116, 12810-12818.

(65) Cussler, E. L. Diffusion: Mass Transfer in Fluid Systems, 1st ed.; Cambridge University Press: New York, 1984.

(66) Holz, M.; Patil, K. J. Cation-Cation Association of Tetramethylammonium Ions in Aqueous Mixed Electrolyte Solutions. Ber. Bunsen-Ges. 1991, 95, 107-113.

(67) Müller, K. J.; Hertz, H. G. A Parameter as an Indicator for Water-Water Association in Solutions of Strong Electrolytes. J. Phys. Chem. 1996, 100, 1256-1265. 